\title{
Mitigating Traffic Congestion: The Role of Intelligent Transportation Systems
}

\author{
Aaron Cheng ${ }^{*}$, Min-Seok Pang ${ }^{\dagger}$, Paul A. Pavlou ${ }^{\ddagger}$
}

\begin{abstract}
Despite massive investments in transportation infrastructure, traffic congestion remains a major societal and public policy problem. Intelligent Transportation Systems (ITS) have been proposed as a potential solution to this challenge, but their effectiveness has remained unclear in both research and practice. To understand whether and how ITS affect traffic congestion, we consolidate a unique longitudinal dataset on road traffic and the deployment of a large federally-supported ITS program in the United States (U.S.) - 511 Systems - in 99 urban areas between 1994 and 2014. The difference-in-differences estimates show that the adoption of 511 Systems is associated with a significant decrease in traffic congestion, saving over $\$ 4.7$ billion dollars and 175 million hours in travel time annually in U.S. cities. 511 Systems also reduce about 53 million gallons of fossil fuel consumption and over 10 billion pounds of $\mathrm{CO}_{2}$ emissions. We offer two theoretical explanations for this effect: (i) ITS help individual commuters to make better travel decisions; and (ii) ITS help local governments to develop an urban traffic management capability. Empirical evidence supports the underlying theoretical mechanisms and shows that ITS help commuters to schedule travel more efficiently, choose better navigation routes, and optimize their work-trip transportation mode. Second, the effect of ITS is contingent upon road supply and public transit services. We also find that the traffic-reducing effect of ITS is larger when commuters use more online services for traffic information and when state governments incorporate more functionalities into their 511 Systems. This study contributes to the literature on IT capabilities, public-sector IT value, and the societal impact of IT, while also extending the transportation economics to IT-enabled traffic interventions. Finally, we inform policymakers of ITS as a cost-effective means to mitigating traffic congestion.
\end{abstract}

Keywords: Intelligent Transportation Systems, Traffic Congestion, Transportation Economics, IT Value, Difference-in-Differences.

(The paper has been accepted for publication at Information Systems Research)

\footnotetext{
* Aaron Cheng, Assistant Professor, London School of Economics

${ }^{\dagger}$ Min-Seok Pang, Associate Professor, Temple University

* Paul A. Pavlou, Professor, University of Houston
} 


\section{Introduction}

According to the 2015 Annual Urban Mobility Scorecard, an average American spends over 41 hours stuck in traffic jams, resulting in almost $\$ 1,000$ in congestion cost per person-year. These figures are more pronounced in large metropolitan areas (e.g., New York City, Los Angeles, Chicago) with 60-hour delays and $\$ 1,376$ in congestion cost per person-year. Not only does traffic congestion cause economic losses to commuters, but it generates excessive greenhouse gas emissions (Barth and Boriboonsomsin 2008). Nationwide, traffic congestion results in an estimated $\$ 159$ billion in costs annually and accounts for 7 billion travel hours, 3 billion gallons of fossil fuel, and 210 billion pounds of $\mathrm{CO}_{2}$ in 471 U.S. urban areas. This poses a major challenge to transportation policymakers and city planners. Over the last several decades, state and local governments in the U.S. have made major infrastructure investments in road expansion, but the massive expenditures on physical transportation infrastructures have not been shown to be very effective in mitigating traffic congestion (e.g., Downs 1962, 1992, Arnott and Small 1994, Duranton and Turner 2011).

Besides transportation infrastructure investments, policymakers have begun leveraging information technology (IT) to combat traffic congestion, most commonly with Intelligent Transportation Systems (ITS). ITS are defined by the U.S. Department of Transportation (USDOT) as "an integrated system of advanced communications technologies embedded in the transportation infrastructure and in vehicles to improve transportation safety and mobility." ${ }^{1}$ Since 2001, a number of U.S. state governments have substantially invested ITS with financial grants from the USDOT. These governments rely on ITS to leverage traffic data collected from sensors and video cameras installed on roads and bridges. For instance, the State of Washington leverages real-time data from its ITS in the Seattle metropolitan area to operate managed-lane highways, adjust speed limits dynamically, and inform drivers of traffic conditions via overhead traffic signals. ${ }^{2}$ ITS enable many state governments to make real-time traffic information publicly available through multiple channels (e.g., telephone information services, websites with interactive traffic

\footnotetext{
${ }^{1}$ http://safety.fhwa.dot.gov/its/, retrieved on January 5, 2019. By definition, navigation and route guidance systems, such as Google Maps, are also classified as ITS. Albeit this, our study mainly focuses on government-adopted ITS that help traffic management not only on the demand side (i.e., commuters) but also on the supply side (i.e., road). Google Traffic have mainly served commuters, and their data, to our knowledge, have rarely been shared with state or local transportation agencies for traffic supply management. ${ }^{2}$ http://www.wsdot.wa.gov/Operations/Traffic/ActiveTrafficManagement/, retrieved on January 5, 2019.
} 
maps, TV and radio broadcasts). With the aid of ITS, state and local governments can effectively manage day-to-day traffic operations, and devise long-term transportation policies to guide future construction plans.

The U.S. federal, state, and local governments spent $\$ 318.2$ billion in transportation in 2018, amounting to $\$ 972$ per capita. ${ }^{3}$ By comparison, annual investments in intelligent transportation only amount to $\$ 100$ million (Government Technology 2010), which accounts for $0.3 \%$ of the total transportation investments. Given the considerable economic and societal costs of traffic congestion (Winston and Langer 2006, Winston 2013) and the potential of ITS to mitigate traffic congestion, this study asks the following two research questions: Do intelligent transportation systems help to mitigate traffic congestion? And, if they do, what are the underlying mechanisms that explain the traffic-mitigation effect?

To answer these questions, we draw upon long-held debates on traffic congestion in the transportation economics (e.g., Downs 1962, Cervero 2002, Duranton and Turner 2011). One central tenet in this literature has been the "induced traffic" (Goodwin 1996, Cervero 2002), which challenges a taken-for-granted assumption that increasing road supply with physical infrastructure investments reduces traffic congestion. On the contrary, "induced traffic" contends that a decrease in driving costs followed by road expansion induces more traffic, and it does not necessarily reduce traffic congestion. As a traffic intervention like road expansion, do ITS have a similar "traffic-inducing" effect? The transportation economics literature suggests that it may not be the case and proposes that traffic congestion can only be tackled by dealing with traffic supply-and-demand simultaneously (Cervero 2002), a solution that ITS could offer to traffic management.

Although the Information Systems (IS) literature has developed an extensive body of knowledge on how IT creates value in both the private and the public sectors (e.g., Melville et al. 2004, Pang et al. 2014a), the IS literature has not paid much attention to transportation, which is an integral part of everyone's life. By integrating the transportation economics with the IS literature on the value of IT, we offer two theoretical explanations on the roles of ITS in mitigating traffic congestion: (i) ITS help commuters to make better travel decisions, and (ii) ITS help local governments to develop an urban traffic management capability.

\footnotetext{
${ }^{3}$ https://www.usgovernmentspending.com/year spending 2018USbn 18bs2n\#usgs302, retrieved on January 5, 2019.
} 
To empirically assess the impact of ITS on traffic congestion, we consolidate a longitudinal dataset of the road stock, traffic volume, congestion costs, and delay hours of 99 urban areas (metropolitan statistical areas or MSA) in the U.S. from 1994 to 2014. We focus on the 511 Traveler Information Systems, the largest federally-supported ITS program in U.S. history, that are dedicated not only to collecting massive real-time traffic data and providing public access to this information, but also to monitoring and analyzing urban mobility patterns and using them to make strategic transportation and infrastructure plans (Auer et al. 2016). To estimate the impact of 511 Systems on traffic congestion, we use a difference-in-differences approach to exploit the deployment pattern of 511 Systems, which has been staggered temporally and geographically across 46 U.S. states since 2001. A battery of robustness tests helps to establish the validity of such an identification strategy, including a leads-and-lags model to test the parallel trend assumption and a discrete time hazard model to evaluate the potential correlates with the 511 Systems implementation.

Econometric analyses yield several key findings. First, we find ITS to significantly mitigate urban traffic congestion. Specifically, the adoption of 511 Systems is associated with a decrease in unnecessary travel time and congestion costs. An average commuter in a metropolitan area that adopted 511 Systems saves about $2.57 \%$ of her commuting time and $2.86 \%$ in extra costs due to traffic congestion. Multiplying those figures by the number of commuters in U.S. urban areas, we find that 511 Systems lead to annual total savings of about 175 million hours in travel time and $\$ 4.72$ billion in travel costs. Second, the adoption of 511 Systems is associated with a decrease in excessive fuel consumption by about 53 million gallons of gasoline and over 10 billion pounds of $\mathrm{CO}_{2}$ in greenhouse gas emissions due to traffic congestion each year nationally, demonstrating a compelling environmental impact of ITS. Further, our back-of-the-envelope calculation shows that the annual economic savings from 511 Systems $(\approx \$ 4.72$ billion $)$ are 35 times higher than their total investment over 10 years $(\approx \$ 135$ million $)$, representing a substantial return on investment in ITS. These findings not only demonstrate the significant effects of ITS but also highlight its costeffectiveness in managing traffic, reducing road congestion, and enhancing environmental sustainability.

Moreover, we take a further step to examine the underlying mechanisms by which ITS help to mitigate traffic congestion, providing unique insights into the critical roles of IT in the transportation sector. 
Utilizing a wide range of additional fine-grained administrative datasets (i.e., American Community Survey Public Use Microdata Samples, National Household Travel Survey, National Transit Data), we obtain a rich spectrum of supportive evidence on the roles of ITS in traffic management on both the traffic supply and the demand side. On the demand side, we find that the adoption of 511 Systems is associated with changes in (i) individual travel patterns (e.g., daily trip frequency and distance), (ii) navigation routes choices, (iii) travel time uncertainty, and (iv) work-trip transportation modes. On the supply side, we find that the effect of 511 Systems on traffic congestion is stronger with larger road supplies and more rail transit services (Section 7). Finally, we examine the impact of the actual usage of ITS on traffic congestion. We show evidence that the traffic-reducing effect of ITS is enhanced with more 511 website visits and with more information provision functionalities in 511 Systems (Section 8).

This study makes important contributions to the IS and the transportation economics literatures. First, by focusing on the long-lasting public concern of traffic congestion, this study extends the emerging literature on the societal impacts of IT to transportation. Second, we contribute to the literature on IT value creation by demonstrating the roles of ITS in traffic management and congestion mitigation. We aim to push the boundary of the IS literature, not only by identifying the significant impact of ITS on traffic congestion, but by unraveling the underlying mechanisms with rich supportive evidence. Third, we contribute to the "Green IT" literature (e.g., Melville 2010, Malhotra et al., 2013) by documenting that ITS help to reduce fuel consumption and carbon emissions. Fourth, we contribute to the transportation economics by stressing the role of ITS as a cost-effective traffic intervention. Finally, by integrating the IS with the transportation literature, we propose a new interdisciplinary approach that sheds light on the increasing role of IT in transportation, an approach that, to our knowledge, few extant studies have attempted in either of the literatures.

This research also provides practical implications for both policymakers and also for commuters. Providing transportation infrastructures is considered as a primary responsibility of governments and a crucial factor for economic development (Winston 2013). This is why transportation spending is one of the largest public-sector expenditures. We seek to influence policy debates on transportation spending by empirically demonstrating that IT can be a cost-effective intervention for managing traffic and mitigating 
congestion. We also explain how policymakers can leverage ITS to develop traffic supply-and-demand coordination. Commuters also benefit from ITS and other emerging traffic management technologies through reduced daily travel times and costs. Finally, for the societal impacts of ITS, we show that ITS increase social welfare, in terms of not only economic savings but also environmental sustainability.

\section{Intelligent Transportation Systems}

Transportation planners in the U.S. have applied technologies to manage traffic since the 1980s, such as navigation routing, electronic toll collection, and traffic measurement (Auer et al. 2016). In 1994, the USDOT officially coined a term "ITS" to recognize the significant potential of IT-enabled interventions in tackling traffic problems. In 2000, upon a USDOT petition, the Federal Communication Commission (FCC) designated "511" as the single traffic information telephone number across the country. ${ }^{4}$ In 2001 , the USDOT started to provide federal grants to U.S. state governments for implementing 511 Traveler Information Systems. By 2011, 70\% of the U.S. population (i.e., over 233 million) was being served by 511 Systems. By 2014, 46 states implemented 511 Systems with federal grants totaling \$135 million.

While 511 Systems started as a simple telephone service for traffic information, they now represent a broader set of sophisticated, intelligent systems for both commuters and state/local governments. Table 1 provides a list of the functionalities and features of a typical 511 System. 511 Systems aim to help both commuters and local governments to make better decisions with real-time traffic information obtained from cameras and sensors on roads/bridges and intelligent processing of said traffic data. Commuters can have access to such real-time traffic data via cellphones, websites, and even smartphone apps recently. ${ }^{5}$ State and local governments can use such information to devise real-time and long-term interventions, such as dynamic toll pricing, lane adjustments, and rescheduling public transit in response to traffic demands.

\footnotetext{
${ }^{4}$ https://www.fhwa.dot.gov/trafficinfo/511what.htm, retrieved on January 5, 2019.

${ }_{5}^{5}$ For instance, according to a traffic report (https://www.udot.utah.gov/main/f?p=100:pg:0:::1:T,V:4254, retrieved on January 5, 2019) by the Utah Department of Transportation, its 511 System had received 20,049 calls and 178,658 sessions of 511 website visits in January 2015. Besides, Utah has 191 variable message signs (VMS) across its roads, and it displayed 41,793 VMS messages with its 511 data in the same month. Such evidence illustrates that drivers do utilize the information from 511 Systems, either proactively via 511 calls and website visits or passively from road signs and TV/radio broadcasts.
} 
Table 1. The Functions, Infrastructure, and Instances of Intelligent Transportation Systems (ITS)

\begin{tabular}{cll}
\hline \hline ITS Functionalities & \multicolumn{1}{c}{ ITS Infrastructures } & \multicolumn{1}{c}{ Instances } \\
\hline Traffic data collection & $\begin{array}{l}\text { Traffic monitoring systems } \\
\text { Road weather monitoring }\end{array}$ & $\begin{array}{l}\text { CCTV cameras, crowdsourcing traffic data from } \\
\text { GPS-equipped cell-phones }\end{array}$ \\
\hline \multirow{5}{*}{ Traffic analytics } & $\begin{array}{l}\text { Data analytics for planning and } \\
\text { performance evaluation }\end{array}$ & Real-time simulation, network prediction \\
& Active traffic management & $\begin{array}{l}\text { Speed harmonization, queue warning, temporary } \\
\text { shoulder use, dynamic merge control, dynamic } \\
\text { lane markings, dynamic routing }\end{array}$ \\
\cline { 2 - 4 } & Driver information provision & $\begin{array}{l}\text { Information provision through smartphone apps, } \\
\text { websites, or telephone call services }\end{array}$ \\
\cline { 2 - 4 } & $\begin{array}{l}\text { Ramp management and } \\
\text { conventional lane management }\end{array}$ & Ramp metering, ramp closure, lane controls \\
\cline { 2 - 4 } & Diversion management & $\begin{array}{l}\text { Divert traffic to avoid incidents, construction, } \\
\text { weather, and events }\end{array}$ \\
\cline { 2 - 3 } & $\begin{array}{l}\text { Integrated systems to assist other } \\
\text { forms of traffic interventions }\end{array}$ & $\begin{array}{l}\text { Electronic road pricing systems, smart parking, } \\
\text { regional transit management systems }\end{array}$ \\
\hline
\end{tabular}

We choose 511 Systems as our research context for three reasons. First, 511 Systems encompass comprehensive IT functionalities and services that integrate traffic data collection, intelligent analytics, and proactive, real-time traffic management. In addition, the infrastructure, IT functionalities, and IT services provided by 511 Systems are relatively standardized and thus have similar effects on traffic congestion across locations, allowing us to regard the adoption of 511 Systems as an identical or a quasi-identical treatment for local traffic congestion once adopted. Second, 511 Systems have gradually been adopted across locations for more than a decade, providing us with a source of variance to compare the differences in traffic congestion between not only MSAs that adopted 511 Systems and those that did not, but also before and after such an adoption in a specific MSA. Third, some potential confounding factors (e.g., demographic and socioeconomic status) can be accounted for by using census data, and some MSA-specific (e.g., geographical location and climate) and year-specific heterogeneities (e.g., nationwide common macroeconomic trends) are arguably fixed or quasi-fixed. This research context, therefore, helps us to develop a robust identification strategy to uncover the effect of ITS adoption on urban traffic congestion.

While our research subject is the 511 Systems developed and deployed by state and local governments since early 2000s, navigation apps such as Google Maps have recently become popular among drivers for individual travel planning and navigation. To stress the importance of our focus on 511 Systems, it is necessary to compare government-adopted ITS and privately-developed commercial navigation systems. 
First, 511 Systems are a comprehensive ITS project to provide information and facilitate decision-making on both the traffic supply and demand sides since 2001, while navigation apps (e.g., Google Maps) have mainly served individual commuters with real-time traffic information only on the demand side since $2009 .^{6}$ Second, although navigation apps are prevalent now, drivers are still influenced directly and indirectly by the information provided by 511 Systems in the U.S,, whether or not they are aware of their existence. ${ }^{7}$ Third, while drivers choose to use or not use navigation apps, they are still required to follow the directions of electronic signs and signals on the roads that are empowered by 511 Systems.

Having said that, in addition to the government-adopted 511 Systems, we also examine the impact of navigation applications developed by the private sector, particularly Google Maps, on traffic congestion (Section 6.7). We estimate how the search intensity of Google Maps is associated with traffic congestion, an exercise that reinforces our theorization on how real-time information helps to manage traffic demand. We offer suggestive evidence on the joint role of Google Maps and 511 Systems in reducing traffic congestion.

\section{Theoretical Development}

To investigate how ITS influence traffic congestion, we draw upon two main bodies of research: (i) the nature of traffic congestion and conventional interventions in the transportation economics literature, and (ii) the IT and business value creation research in the IS literature. The transportation economics provides a theoretical foundation for the economic account of traffic congestion and traffic supply-and-demand, while the IS literature helps us to understand how ITS can help execute effective traffic management.

\subsection{Traffic Congestion and Conventional Interventions to Mitigate Traffic Congestion}

Traffic congestion has been discussed extensively in the transportation economics for the past half a century

(e.g., Downs 1962, Vickrey 1969, Arnott and Small 1994, Duranton and Turner 2011). Transportation economists view traffic congestion as a negative externality that arises when drivers do not bear the full costs of the impact (i.e., traffic) from their driving (Small and Verhoef 2007). Therefore, one ideal solution

\footnotetext{
${ }^{6}$ https://electronics.howstuffworks.com/how-does-google-maps-predict-traffic.htm, retrieved on January 5, 2019.

7 According to a report on Kentucky's 511 Traveler information Systems (Van Dyke et al. 2016), while 28\% of the drivers obtain information from Google Maps or Waze and 5\% from in-car navigation systems, up to $62 \%$ drivers directly and indirectly obtain traffic information from 511 Systems: Among them, $42 \%$ from TV and radio broadcasts which use 511 data for traffic news reports, 13\% directly from 511 services, and 7\% from social media accounts of state or local transportation agencies (e.g., @511SFBay, a twitter account for 511 traffic information in San Francisco Bay Area).
} 
for traffic congestion in economics is to price these negative externalities (Jones 1998). If drivers do not pay for the time loss they impose on others, they make socially-inefficient driving choices (Arnott and Small 1994). Extensive research in the past few decades (e.g., Vickrey 1969, Arnott 2001) has examined how to price traffic congestion to mitigate the negative externality. However, congestion pricing as a tool to improve urban mobility has received little attention from policymakers (e.g., Jones 1998).

Instead, policymakers have been in favor of an alternative intervention, namely "build our way out" for the past half a century (Arnott and Small 1994). Merely expanding the road supply, however, is generally considered ineffective or even counter-productive (e.g., Goodwin 1996). This is due to a phenomenon of "induced traffic," which occurs when latent travel demands are induced due to a decrease in driving costs after road expansion (Goodwin 1996, Cervero 2002). Downs $(1962,1992)$ calls induced traffic "the Fundamental Law of Highway," later generalized by Duranton and Turner (2011) to a broader class of major urban roads. This literature thus argues that the "build our way out" approach is not effective since it only considers the supply side and lacks a foresight to coordinate supply and demand in tandem (e.g., Cervero 2002). In this study, we propose ITS as a cost-effective intervention for traffic congestion by coordinating traffic supply and demand simultaneously, a new theoretical angle in transportation economics.

A small stream of transportation economics studies has discussed traffic information provision as a potential intervention for better allocating road traffic (e.g., Emmerink et al. 1996, Verhoef et al. 1996). This line of work adopts a microeconomics perspective and builds analytical models on how information provision by navigation systems for drivers affects both their travel decisions and overall traffic congestion (Arnott et al. 1991). However, simulation findings have been mixed on whether navigation systems help to reduce congestion (Small and Verhoef 2007). On the one hand, information from navigation systems can help drivers to make more informed route choices and thus reduce excess travel (Ben-Akiva et al. 1991). On the other hand, if many drivers receive the same information, they might choose similar routes and departure times, causing traffic congestion (Arnott et al. 1991). In this study, we expand and contribute to this literature in three unique ways: (i) unlike navigation apps for drivers (e.g., Google Maps), the focus of this study is a comprehensive ITS program (i.e., 511 Systems) that informs both drivers and state/local 
governments; (ii) we offer empirical evidence to reconcile the tension on whether information provision mitigates or exacerbates traffic congestion, thereby complementing extant analytical work (e.g., Arnott et al. 1991); and (iii) we examine how the effect of information provision on traffic congestion interacts with conventional interventions (e.g., road-supply adjustment) for traffic management.

\subsection{Information Technology and Value Creation}

To theorize how ITS can be utilized for traffic management, we draw upon the IS literature to understand the role of IT in organizations (government agencies0 and people's individual lives.

A key role of IT is to collect, transmit, store, process, and utilize information (Shapiro and Varian 1998, pp. 8). IT creates value with its information by reducing different types of costs associated with economic activities, such as search costs (Goldfarb and Tucker 2019). IT can inform first-line workers and managers and decentralize decision-making (Bloom et al. 2014). IT enables the exchange of information in electronic markets for greater firm and consumer surplus (Granados et al. 2006). The role of information has also been stressed in the growing literature of the broader societal impacts of IT. This line of work has touched upon a few sensitive topics, such as the spread of HIV (Chan and Ghose 2014) and alcohol-related motor vehicle homicides (Greenwood and Wattal 2017). The key mechanism in these studies is that ITenabled platforms (e.g., Craigslist, Uber) reduce information asymmetry and decrease search and transaction costs. In our setting, ITS make traffic information more accessible and transparent, lowering costs for drivers to optimize their travel decisions and helping local governments to improve traffic conditions. Our study thus extends the research on the broader societal role of IT in managing traffic.

Another role of IT is about technological changes that advanced technologies and information infrastructures bring for effective management (Brynjolfsson and Hitt 2003). The IS literature mainly focuses on IT in the private sector and discussed the business value of IT (e.g., Pavlou and El Sawy 2006, Rai et al. 2012). Its main theoretical perspective stresses that IT resources can improve organizational performance by developing relevant IT capabilities. Bharadwaj et al. (2002) define IT capabilities as the "firm's ability to acquire, deploy, and leverage its IT resources to shape and support its business strategies and value chain activities." In the recent development of IT capabilities, coordination capabilities stress 
the role of IT to co-create relational value within a firm (Bharadwaj et al. 2007) or within a value chain (Rai et al. 2012), while reconfiguration (dynamic or improvisational) capabilities stress the ability of IT to pro-actively or spontaneously, respectively, reconfigure existing resources to build operational capabilities in response to turbulent environments (Pavlou and El Sawy 2010). Beyond the private sector, a burgeoning literature has begun to theorize IT value in the public sector (e.g., Pang et al. 2014a, 2016). This literature argues that IT resources can be used to create societal value by developing public-sector IT capabilities.

Drawing on the IT capability literature, our study argues that ITS help local governments to develop an IT-leveraging traffic management capability, which we define as the ability of local transportation agencies to leverage ITS infrastructure and functionalities (Table 1) to deliver value-added services to the public. Our perspective on IT-leveraging traffic management capabilities deepens our understanding of how ITS can be integrated with extant traffic interventions to better manage traffic and mitigate congestion.

\subsection{Intelligent Transportation Systems and Traffic Congestion}

Integrating the IS and transportation economics literature, we develop two theoretical explanations by which ITS mitigate traffic congestion. First, ITS inform commuters of traffic conditions and facilitate their decision making on travel planning and navigation. Without ITS, drivers may make such decisions based on their own intuitions or experiences, which are unlikely to be accurate. With ITS, drivers can schedule their travel beforehand by obtaining real-time traffic information via 511 calls or 511 websites with interactive traffic maps. In addition, they can read roadside variable message signs (VMS) and be aware of traffic situations ahead of them on roads on a real-time basis. All reliable traffic information disseminated via various channels from ITS facilitates drivers' individual travel decisions on departure times, transportation modes, and navigation routes (Small and Verhoef 2007). These changes in micro-level commuting decisions can shift the pattern of overall traffic demand to be more temporal and geographical dispersed, thereby mitigating traffic congestion (e.g., Arnott and Small 1994, Duranton and Turner 2011).

Second, ITS inform local governments and transportation agencies of real-time traffic conditions and help them develop an urban traffic management capability. ITS enable local governments to adjust road supply proactively in response to potential traffic congestion. For instance, on the busiest stretch of 
Interstate 5, the Washington State Department of Transportation manages traffic with overhead high-tech gantries that display speed limits and automatically adjust the onsite traffic conditions, with yellow arrows to merge, green arrows to show open lanes, and red X to mark closed lanes (Government Technology 2011a). Such VMS help adjust the road supply and allocate traffic demand more efficiently. ITS also enable local governments to develop IT-leveraging traffic management capabilities that (i) integrate the strengths of existing traffic interventions and (ii) facilitate proactive supply-side solutions for traffic management. Conventional interventions, such as road expansion and pricing, are often individually and independently designed and deployed to manage traffic (Papageorgiou et al. 2003). Consistent with IT-enabled coordination capabilities in organizations (Bharadwaj et al. 2007), ITS can coordinate existing traffic interventions to enhance their effects. For instance, in 2009, the New York City (NYC) Department of Transportation collected GPS data from 13,000 taxis to identify the most congested roads. Based on these data, it closed off the Times Square and Herald Square sections of Broadway Avenue to traffic to eliminate the confusion from the diagonal trajectory of Broadway Avenue. The speed of taxis in both directions has improved by $15 \%$ after this intervention (Government Technology 2011b). Besides, ITS can reconfigure existing resources (e.g., roads, toll stations) to help local governments to develop a dynamic traffic management capability in response to traffic shocks. ITS-enabled traffic solutions include dynamic fare adjustment in public transportation, ${ }^{8}$ dynamic High-Occupancy Vehicle (HOV)/managed lanes, ${ }^{9}$ and dynamic pricing of toll roads and highways. We argue that such IT-enabled reconfiguration capabilities, as in organizations (Pavlou and El Sawy 2006), enhance the dynamic capability of local governments to manage urban traffic. These examples illustrate how ITS can enhance the traffic management capability of local governments.

In sum, we argue that ITS can help to mitigate traffic congestion by (i) assisting drivers to make better travel decisions, and (ii) helping local governments to develop an IT-enabled traffic management capability.

\footnotetext{
${ }^{8}$ https://ops.fhwa.dot.gov/atdm/approaches/adm.htm, retrieved on January 5, 2019.

${ }_{9}^{9} \mathrm{HOV}$ lanes (also known as carpool lanes) are restricted lanes reserved at peak hours for exclusive use by vehicles with a driver and one or more passengers. Managed lanes can dynamically change the qualifications for driving in an HOV lane.
} 


\section{Data and Methodology}

\subsection{Data}

To empirically assess the impact of ITS on traffic congestion, we consolidate a longitudinal dataset of 99

U.S. Metropolitan Statistical Areas (MSAs) (Figure 1) over a period of 21 years from 1994 to 2014 by integrating multiple data sources. The unit of analysis is an MSA as designated by the U.S. Census Bureau.

The main analysis relies on the traffic data from the Annual Urban Mobility Scorecard (AUMS) maintained by the Texas A\&M Transportation Institute. The AUMS is a comprehensive dataset that integrates highway performance data from the Federal Highway Administration (FHA), and traffic speed data collected by INRIX ${ }^{10}$ on 1.3 million miles of U.S. urban streets and highways. The AUMS data have been widely used in transportation economics research (e.g., Fagnant and Kockelman 2015). To incorporate road network information, we matched AUMS dataset with the Highway Performance Monitoring Systems (HPMS) data for each MSA. The HPMS data, also widely used in transportation economics (e.g., Duranton and Turner 2011), contains administrative and roadway system information (e.g., road miles, vehicle miles traveled) on all public roads, including interstate highways, freeways, arterials/collectors, and local roads.

Our sample is restricted to 99 MSAs, as the AUMS only provides traffic congestion data for 101 U.S. urban $\operatorname{areas}^{11}$ (See Table A1 in Appendix A). Albeit unavailable for other MSAs, to our knowledge, the AUMS is the only publicly-accessible source covering most comprehensive congestion information of U.S. cities. Our timeframe begins at 1994, which allows us to capture at least 7 years of pre-intervention traffic trends for each MSA, as 2001 is the first year that an MSA (Omaha, NE-IA) started to adopt 511 Systems. ${ }^{12}$ The timeframe ends at 2014 after which up-to-date information on 511 Systems adoption is not available.

The main dependent variable is CONGESTION, measured by the log-transformed annual congestion costs per commuter (COST) and the annual hours of delay per commuter (TIME) for each MSA from the AUMS dataset. As standard measures for traffic congestion in the transportation economics (Dewees 1979), COST and TIME indicate the amount of extra time and costs, respectively, incurred due to traffic congestion.

\footnotetext{
${ }^{10}$ INRIX is a global company which provides Internet services and mobile applications of road traffic and driver services.

${ }^{11}$ We dropped two MSAs (Indio-Cathedral City-Palm Springs, CA, Lancaster-Palmdale, CA) as they fail to match HPMS data.

${ }^{12}$ We do not incorporate data earlier than 1994 for the following reasons. First, different data sources, such as employment and transportation, have various degrees of availability in the early 1990s and before, causing numerous missing values if we combine the datasets. Second, most relevant datasets before 1994 were not well-documented or well-archived, creating difficulties to obtain reliable data points. Last and importantly, the long pre-intervention period suffices to capture most variations between MSAs.
} 
COST is calculated based on delay costs and fuel costs during idling, while TIME is based on the difference between actual travel speeds and congestion-free speeds. For an MSA, we use average congestion per commuter, instead of aggregate measures (e.g. total congestion costs), in the main analysis for the ease of interpretation and comparison across MSAs. Besides, we use extra greenhouse gas emission $\left(\mathrm{CO}_{2}\right)$ and fuel consumption (FUEL) due to congestion as alternative dependent variables (e.g., Rothenberg 1970, Chen and Whalley 2012). We also use aggregate traffic volume, measured by Vehicle-Miles $\operatorname{Travel}^{16}(V M T)$ from the HPMS data to measure MSA-level traffic demand (Duranton and Turner 2011).

The independent variable of interest is the indicator ITS, which represents whether 511 Systems have been implemented and operated given a specific MSA and year (as determined by Table 2). The data for ITS are directly retrieved from the website of the FHA. Note that 511 Systems have mostly been adopted by state governments with a few exceptions (e.g., local governments in California such as San Francisco made independent decisions). We match 511 Systems adoption data with our main AUMS dataset to each MSA and each year. Generally, most urban areas in our sample (77 out of 99) are bounded within a single state; however, some span across two or more states (e.g., Philadelphia-Camden-Wilmington, PA-NJ-DEMD, MSA), where drivers can benefit from 511 Systems from different states. For such cross-state MSAs, we calculate the road miles-percentages of MSA in each state as weights and create weighted-average ITS measures. ${ }^{17}$ Table 2 and Figure 2 show the 511 Systems adoption year by locations. By 2014, 68 out of the 99 MSAs (69\%) in our sample had adopted 511 Systems. Setting the remaining as untreated MSAs throughout our timeframe allows us to compare congestion across treated and untreated MSAs over the same timeframe using a difference-in-differences framework (Angrist and Pischke 2008, pp. 227).

To account for potential confounding factors that might be correlated with both ITS adoption and traffic congestion, we incorporate a rich set of time-varying MSA-level covariates, including population, personal income, total road miles, commuter proportion, fuel costs, public transit, commercial traffic,

\footnotetext{
${ }^{16} \mathrm{VMT}$ is calculated by multiplying the amount of daily traffic on a roadway segment by the length of the segment and then summing all the segments' VMT for an MSA.

${ }^{17}$ For example, in the Philadelphia-Camden-Wilmington MSA in the year of 2008, the percentage of roadway miles in Pennsylvania, New Jersey, Maryland, and Delaware is $63.39 \%, 26.63 \%, 0.6 \%$ and $9.34 \%$, respectively. In 2008, only New Jersey adopted a 511 system, and therefore ITS for this cross-state MSA is calculated as 0.2663 .
} 

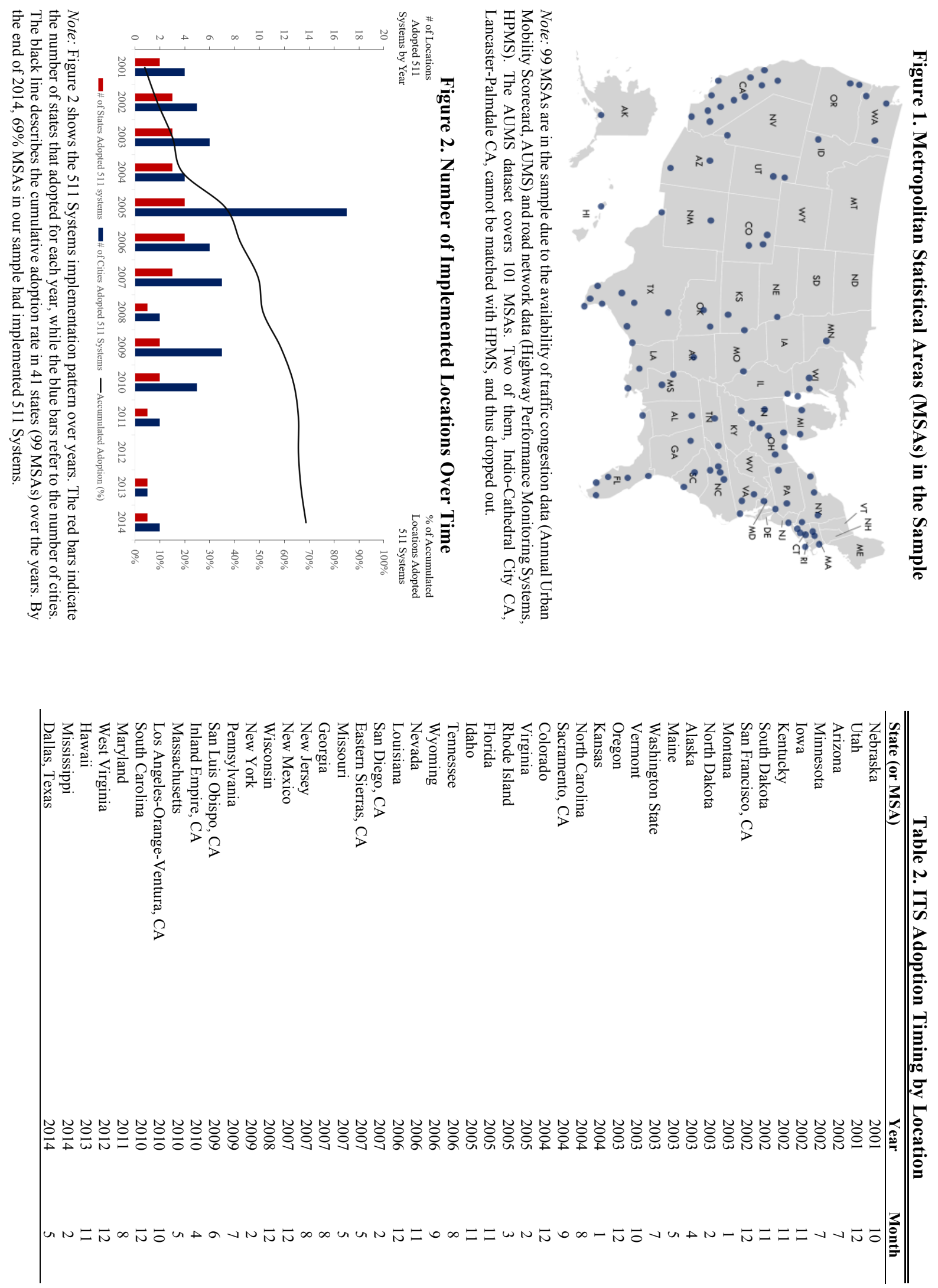
Table 3. Main Variables, Definitions, and Data Sources

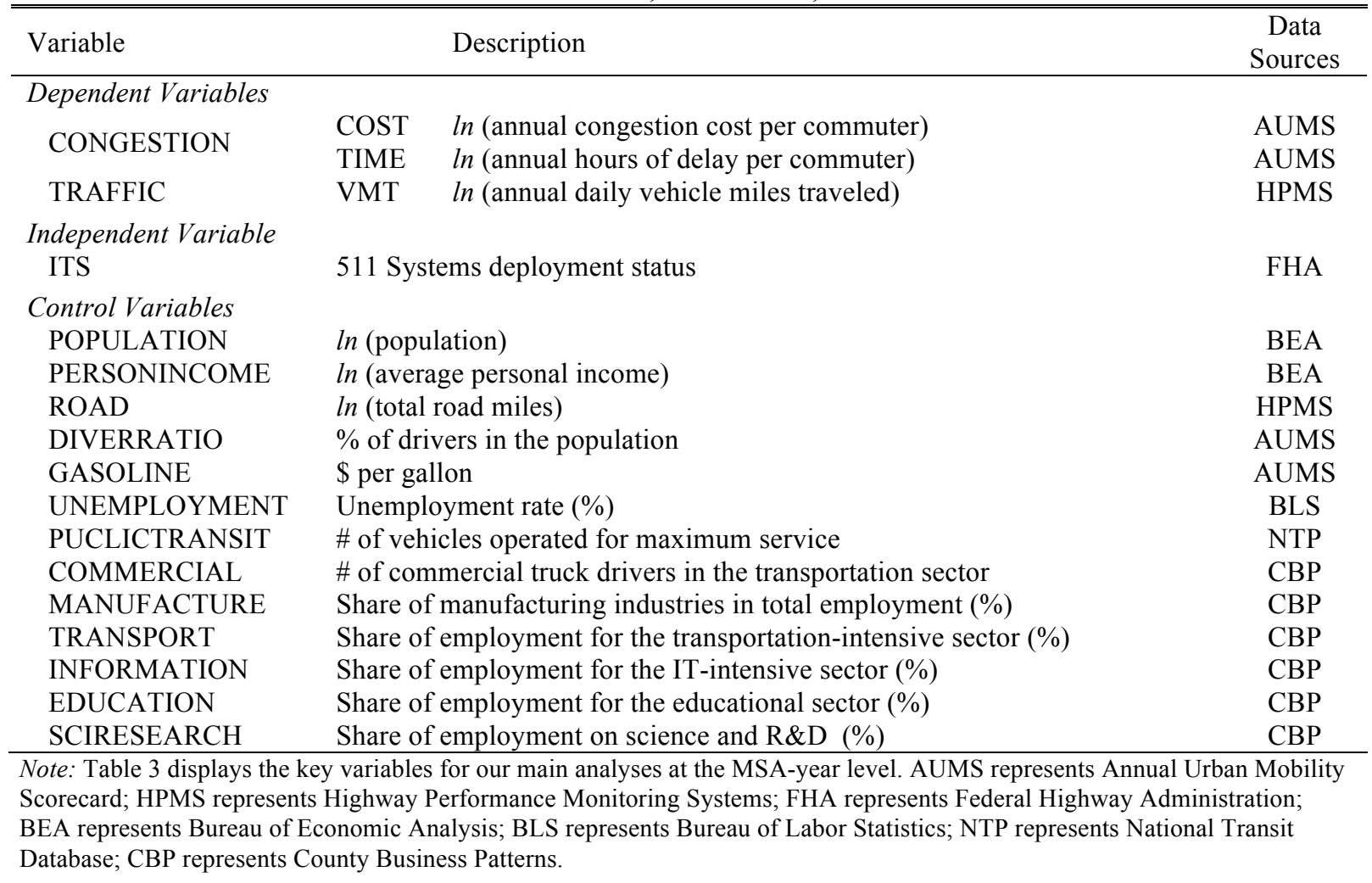

Table 4. Summary Statistics of the Main Variables

\begin{tabular}{llcccc}
\hline \hline & & Mean & Std. Dev & Min & Max \\
\cline { 3 - 6 } & & $(1)$ & $(2)$ & $(3)$ & $(4)$ \\
\hline$[1]$ & COST & 6.773 & 0.386 & 4.625 & 7.635 \\
{$[2]$} & TIME & 3.588 & 0.363 & 1.792 & 4.466 \\
{$[3]$} & VMT & 9.907 & 1.017 & 12.647 & 7.225 \\
{$[4]$} & ITS & 0.278 & 0.440 & 0 & 1 \\
{$[5]$} & POPULATION & 5.551 & 0.327 & 4.744 & 8.607 \\
{$[6]$} & PERSONINCOME & 10.399 & 0.360 & 1.099 & 11.569 \\
{$[7]$} & ROAD & 8.190 & 0.888 & 5.700 & 10.707 \\
{$[8]$} & DRIVERRATIO & 0.473 & 0.045 & 0.234 & 0.550 \\
{$[9]$} & UNEMPLOYMENT & 0.060 & 0.025 & 0.015 & 0.199 \\
{$[10]$} & GASOLINE & 2.172 & 0.921 & 0.930 & 4.350 \\
{$[11]$} & MANUFACTURE & 0.115 & 0.060 & 0.008 & 0.671 \\
{$[12]$} & TRANSPORT & 0.037 & 0.023 & 0.007 & 0.229 \\
{$[13]$} & COMMERCIAL & 8.519 & 1.133 & 2.303 & 11.225 \\
{$[14]$} & PUBLICTRANSIT & 6.189 & 1.451 & 0 & 10.180 \\
{$[15]$} & INFORMATION & 0.029 & 0.013 & 0.002 & 0.140 \\
{$[16]$} & EDUCATION & 0.026 & 0.020 & 0.002 & 0.218 \\
{$[17]$} & SCIRESEACH & 0.063 & 0.041 & 0.003 & 0.325 \\
\hline
\end{tabular}

Note: 2,079 observations for 99 MSAs in 1994-2014. To reduce possible multicollinearity due to a correlation between population and road miles, POPULATION is a weighted measure, that is, the average population per road mile in an MSA in a given year. 
unemployment rates, and employment distribution in related sectors (Table 3) for each MSA over our study period, following extant transportation studies (e.g., Duranton and Turner 2011, Hsu and Zhang 2014). Data for these covariates are collected from multiple sources. We use population and personal income from the Bureau of Economic Analysis (BEA), road supply data from HPMS, and public transit and commercial traffic using National Transit Data (NTD) and County Business Patterns (CBP) data. We measure unemployment rates using data from the Bureau of Labor Statistics (BLS) and employment shares in related sectors (i.e., manufacture, transportation, information, education, science and research) using the CBP data. These variables account for time-variant heterogeneity across years and MSAs. Data sources, measures, summary statistics, and a correlation matrix are shown in Tables 3, 4, and B1 in Appendix B, respectively.

\subsection{Identification Strategy}

Since our empirical design relies on the staggered implementation of 511 Systems across years and MSAs, we adopt a difference-in-differences (DID) approach. As such, we estimate the change in traffic congestion in treated MSAs before and after the adoption of 511 Systems, compared to that in untreated MSAs over the same timeframe. We also incorporate time-varying covariates and year- and MSA-specific fixed effects to account for unobserved invariant heterogeneity across time and locations. We model traffic congestion $\left(\right.$ CONGESTION $\left._{i t}\right)$ in MSA $i$ at year $t$ using the following specification:

$$
\operatorname{CONGESTION}_{i t}=\text { BITS }_{i t}+\gamma X_{i t}+u_{i}+v_{t}+\varepsilon_{i t}
$$

The variable ITS $i t$ indicates the deployment status of 511 Systems in MSA $i$ as of year $t$. COST and TIME are our primary measures for CONGESTION. $u_{i}$ is a vector of 99 MSA fixed-effects; $v_{t}$ is a vector of year fixed-effects, accounting for common nationwide trends in macroeconomic and transportation dynamics; $X_{i t}$ is a vector of time-varying covariates (Table 3 ). $\varepsilon_{i t}$ is the error term, clustered at the MSA level to account for autocorrelation within MSAs over time (Bertrand et al. 2004). We expect the coefficient on ITS $(\beta)$ to be negative if the adoption of 511 Systems helps to mitigate traffic congestion.

It is noteworthy that most decisions in 511 Systems adoption were made by state governments, while our analysis is at the MSA level. States may choose to implement ITS by considering traffic conditions across more than one MSA. For instance, Florida has seven MSAs, but traffic congestion at one MSA alone 
(e.g., Jacksonville, FL) might be unlikely to drive the state-wise adoption decision about ITS. In addition, many MSAs are located across states (e.g., Kansas City, MO-KS), and traffic congestion in such MSAs are unlikely to lead multiple states to adopt ITS in tandem. These two features in our empirical context suggest that reverse causality might not be as serious as the situation that all ITS implementation decisions were made by local governments. This does not, however, imply that ITS adoption is completely exogenous to traffic congestion. We further tackle the remaining validity concerns with a battery of robustness tests, such as the leads and lags model and instrumental variables analyses in Section 6. Besides, we deepen our inquiry into the usage of ITS and its impact on traffic congestion by exploiting data on 511 Systems functionality deployment and telephone calls and websites visits to 511 Systems in Section 8.

\section{Results}

\subsection{Main Results}

Table 5 reports the main results from the DID estimation. In Columns 1 and 2, the coefficients on ITS are negative and significant, representing a $2.86 \%$ decrease in traffic congestion costs and a $2.57 \%$ decrease in traffic delays. This indicates that, on average, a commuter at a metropolitan area that adopted a 511 System saves approximately $\$ 28$ and 63 minutes per year. ${ }^{18}$ By multiplying the number of commuters in large U.S. urban areas, we estimate the total annual savings to be $\$ 4.72$ billion at the national level, emphasizing the substantial impacts of ITS in mitigating traffic congestion. This finding supports our proposition that ITS help to reduce traffic congestion. Our estimation also examines whether ITS induce traffic. In Column 5 with traffic volume $(V M T)$ as the dependent variable, the coefficient of ITS is insignificant, failing to show that ITS induce more traffic. Consistent with the transportation economics studies (e.g., Duranton and Turner 2011, Hsu and Zhang 2014), the coefficient of road supply (Road) is positive and significant (Column 5), indicating that road expansion does induce traffic. By comparing the coefficients of ITS and Road, we find that ITS can be more effective in mitigating traffic congestion than building more roads.

Table 5. Effects of 511 Systems Adoption on Congestion and Road Traffic Volume (DID Models)

\begin{tabular}{lccccc}
\hline \hline & COST & TIME & FUEL & CO2 & VMT \\
\cline { 2 - 6 } & $(1)$ & $(2)$ & $(3)$ & $(4)$ & $(5)$ \\
\hline ITS & $-0.029 * * *$ & $-0.026 * * *$ & $-0.017 * * *$ & $-0.049 * * *$ & 0.019
\end{tabular}

\footnotetext{
${ }^{18}$ The cost and time savings are estimated by multiplying $2.86 \%$ by $\$ 968$ (average congestion cost per commuter in 2014 ) and multiplying $2.57 \%$ by 41 hours (average delay hours per commuter in 2014).
} 


\begin{tabular}{|c|c|c|c|c|c|}
\hline & $(0.006)$ & $(0.006)$ & $(0.006)$ & $(0.014)$ & $(0.023)$ \\
\hline POPULATION & $\begin{array}{c}1.023 * * * \\
(0.037)\end{array}$ & $\begin{array}{c}0.021 \\
(0.035)\end{array}$ & $\begin{array}{c}0.902 * * * \\
(0.033)\end{array}$ & $\begin{array}{l}-0.107 \\
(0.104)\end{array}$ & $\begin{array}{c}0.367 * * * \\
(0.114)\end{array}$ \\
\hline PERSONINCOME & $\begin{array}{c}0.003 \\
(0.009)\end{array}$ & $\begin{array}{c}0.001 \\
(0.009)\end{array}$ & $\begin{array}{c}0.003 \\
(0.009)\end{array}$ & $\begin{array}{l}0.266^{*} \\
(0.147)\end{array}$ & $\begin{array}{c}0.002 \\
(0.006)\end{array}$ \\
\hline ROAD & $\begin{array}{c}1.032 * * * \\
(0.037)\end{array}$ & $\begin{array}{c}0.033 \\
(0.035)\end{array}$ & $\begin{array}{c}0.912 * * * \\
(0.032)\end{array}$ & $\begin{array}{l}-0.021 \\
(0.101)\end{array}$ & $\begin{array}{c}1.146^{* * *} \\
(0.121)\end{array}$ \\
\hline DRIVERRATIO & $\begin{array}{c}1.740 * * * \\
(0.212)\end{array}$ & $\begin{array}{c}0.415^{* *} \\
(0.209)\end{array}$ & $\begin{array}{c}1.552 * * * \\
(0.202)\end{array}$ & $\begin{array}{c}-2.959 * * * \\
(0.848)\end{array}$ & $\begin{array}{c}0.133 \\
(0.516)\end{array}$ \\
\hline GASOLINE & $\begin{array}{c}0.067 * * \\
(0.026)\end{array}$ & $\begin{array}{l}0.053 * * \\
(0.026)\end{array}$ & $\begin{array}{l}0.043 * \\
(0.023)\end{array}$ & $\begin{array}{c}-0.160 * * \\
(0.080)\end{array}$ & $\begin{array}{l}-0.063 \\
(0.049)\end{array}$ \\
\hline UNEMPLOYMENT & $\begin{array}{c}-1.370 * * * \\
(0.249)\end{array}$ & $\begin{array}{c}-1.287 * * * \\
(0.234)\end{array}$ & $\begin{array}{c}-1.163 * * * \\
(0.215)\end{array}$ & $\begin{array}{c}-2.435 * * * \\
(0.641)\end{array}$ & $\begin{array}{l}-0.220 \\
(0.402)\end{array}$ \\
\hline COMMERCIAL & $\begin{array}{c}0.016^{* * *} \\
(0.003)\end{array}$ & $\begin{array}{c}0.015 * * * \\
(0.003)\end{array}$ & $\begin{array}{c}0.015 * * * \\
(0.003)\end{array}$ & $\begin{array}{c}0.064 * * * \\
(0.022)\end{array}$ & $\begin{array}{l}-0.004 \\
(0.007)\end{array}$ \\
\hline PUBLICTRANSIT & $\begin{array}{c}0.028 * * * \\
(0.006)\end{array}$ & $\begin{array}{c}0.025 * * * \\
(0.005)\end{array}$ & $\begin{array}{c}0.015 * * * \\
(0.005)\end{array}$ & $\begin{array}{c}0.022 \\
(0.028)\end{array}$ & $\begin{array}{c}0.028 \\
(0.020)\end{array}$ \\
\hline MANUFACTURE & $\begin{array}{l}-0.011 \\
(0.088)\end{array}$ & $\begin{array}{l}-0.009 \\
(0.084)\end{array}$ & $\begin{array}{c}0.041 \\
(0.076)\end{array}$ & $\begin{array}{l}0.453^{*} \\
(0.248)\end{array}$ & $\begin{array}{c}0.047 \\
(0.177)\end{array}$ \\
\hline TRANSPORT & $\begin{array}{l}-0.498 \\
(0.330)\end{array}$ & $\begin{array}{l}-0.406 \\
(0.311)\end{array}$ & $\begin{array}{l}-0.506^{*} \\
(0.299)\end{array}$ & $\begin{array}{c}-3.063 * * \\
(1.211)\end{array}$ & $\begin{array}{c}0.030 \\
(0.910)\end{array}$ \\
\hline INFORMATION & $\begin{array}{c}0.426 \\
(0.261)\end{array}$ & $\begin{array}{c}0.347 \\
(0.255)\end{array}$ & $\begin{array}{c}0.338 \\
(0.234)\end{array}$ & $\begin{array}{c}2.010 * * * \\
(0.751)\end{array}$ & $\begin{array}{l}-0.288 \\
(0.541)\end{array}$ \\
\hline EDUCATION & $\begin{array}{c}-0.473 * * \\
(0.223)\end{array}$ & $\begin{array}{c}-0.442 * * \\
(0.224)\end{array}$ & $\begin{array}{c}-0.377^{*} \\
(0.204)\end{array}$ & $\begin{array}{c}0.130 \\
(0.823)\end{array}$ & $\begin{array}{c}0.572 \\
(0.595)\end{array}$ \\
\hline SCIRESEARCH & $\begin{array}{c}-0.823^{* * * *} \\
(0.090)\end{array}$ & $\begin{array}{c}-0.777 * * * \\
(0.080)\end{array}$ & $\begin{array}{c}-0.564^{* * * *} \\
(0.077)\end{array}$ & $\begin{array}{l}-0.178 \\
(0.384)\end{array}$ & $\begin{array}{l}-0.093 \\
(0.185)\end{array}$ \\
\hline $\begin{array}{l}\text { MSA FE } \\
\text { Year FE }\end{array}$ & $\begin{array}{l}\text { YES } \\
\text { YES }\end{array}$ & $\begin{array}{l}\text { YES } \\
\text { YES }\end{array}$ & $\begin{array}{l}\text { YES } \\
\text { YES }\end{array}$ & $\begin{array}{l}\text { YES } \\
\text { YES }\end{array}$ & $\begin{array}{l}\text { YES } \\
\text { YES }\end{array}$ \\
\hline $\begin{array}{l}\text { \# of Observations } \\
\text { \# of MSAs }\end{array}$ & $\begin{array}{c}2,079 \\
99\end{array}$ & $\begin{array}{c}2,079 \\
99\end{array}$ & $\begin{array}{c}2,079 \\
99\end{array}$ & $\begin{array}{c}1,089 \\
99\end{array}$ & $\begin{array}{c}2,079 \\
99\end{array}$ \\
\hline Adj. R-squared & 0.956 & 0.954 & 0.970 & 0.919 & 0.986 \\
\hline
\end{tabular}

Note: Table 5 reports results from difference-in-differences regressions on road congestion measured COST, TIME, FUEL, CO2 (data available for 2001-2014) and road traffic demand measured by VMT. Heteroscedasticity-adjusted standard errors, clustered at the MSA level, are included in parentheses. ${ }^{* * *} \mathrm{p}<0.01,{ }^{* *} \mathrm{p}<0.05, * \mathrm{p}<0.1$.

\subsection{Difference-in-Differences Estimation with Leads and Lags of ITS Implementation}

While DID estimates are compelling, it is important to note that they are subject to critical assumptions.

The primary one is the parallel trend assumption that requires no heterogeneity in traffic congestion prior to 511 Systems adoption between treated and untreated MSAs (Bertrand et al. 2004, Angrist and Pischke 2008, pp. 231). This assumption could not be satisfied if unobservable factors, idiosyncratic to individual MSAs, cause pre-treatment heterogeneity in traffic congestion. For example, if 511 Systems have been treated as a pilot project that was adopted early in MSAs with light traffic (e.g., Salt Lake City), we may 
Table 6. DID Estimation on Leads and Lags of 511 Systems Adoption on Traffic Congestion and Traffic Volume

\begin{tabular}{|c|c|c|c|}
\hline & COST & TIME & VMT \\
\hline & (1) & (2) & (3) \\
\hline \multirow[t]{2}{*}{ Pre-ITS $(<=-10)$} & 0.020 & 0.021 & -0.043 \\
\hline & $(0.033)$ & $(0.031)$ & $(0.033)$ \\
\hline \multirow{2}{*}{ Pre-ITS (-9) } & 0.026 & 0.025 & -0.035 \\
\hline & $(0.025)$ & $(0.024)$ & $(0.025)$ \\
\hline \multirow{2}{*}{ Pre-ITS (-8) } & 0.018 & 0.017 & -0.039 \\
\hline & $(0.022)$ & $(0.021)$ & $(0.025)$ \\
\hline \multirow{2}{*}{ Pre-ITS (-7) } & 0.017 & 0.018 & -0.028 \\
\hline & $(0.019)$ & $(0.018)$ & $(0.022)$ \\
\hline \multirow{2}{*}{ Pre-ITS (-6) } & 0.017 & 0.017 & -0.029 \\
\hline & $(0.016)$ & $(0.016)$ & $(0.023)$ \\
\hline \multirow{2}{*}{ Pre-ITS (-5) } & 0.008 & 0.009 & -0.033 \\
\hline & $(0.014)$ & $(0.013)$ & $(0.022)$ \\
\hline \multirow{2}{*}{ Pre-ITS (-4) } & 0.010 & 0.013 & -0.027 \\
\hline & $(0.011)$ & $(0.010)$ & $(0.020)$ \\
\hline \multirow{2}{*}{ Pre-ITS (-3) } & 0.009 & 0.008 & -0.024 \\
\hline & $(0.008)$ & $(0.008)$ & $(0.019)$ \\
\hline \multirow{2}{*}{ Pre-ITS (-2) } & 0.007 & 0.009 & -0.009 \\
\hline & $(0.005)$ & $(0.005)$ & $(0.011)$ \\
\hline Pre-ITS $(-1)$ & & Omitted Baseline & \\
\hline ITS (adoption year) & $\begin{array}{c}0.000 \\
(0.004)\end{array}$ & $\begin{array}{c}0.002 \\
(0.004)\end{array}$ & $\begin{array}{c}-0.002 \\
(0.007)\end{array}$ \\
\hline Post-ITS (1) & $\begin{array}{l}-0.007 \\
(0.009)\end{array}$ & $\begin{array}{l}-0.002 \\
(0.008)\end{array}$ & $\begin{array}{l}-0.001 \\
(0.010)\end{array}$ \\
\hline Post-ITS (2) & $\begin{array}{l}-0.014 \\
(0.011)\end{array}$ & $\begin{array}{l}-0.011 \\
(0.011)\end{array}$ & $\begin{array}{r}-0.009 \\
(0.013)\end{array}$ \\
\hline Post-ITS (3) & $\begin{array}{l}-0.018 \\
(0.014)\end{array}$ & $\begin{array}{l}-0.016 \\
(0.014)\end{array}$ & $\begin{array}{c}-0.002 \\
(0.017)\end{array}$ \\
\hline Post-ITS (4) & $\begin{array}{l}-0.026 \\
(0.016)\end{array}$ & $\begin{array}{l}-0.024 \\
(0.015)\end{array}$ & $\begin{array}{r}0.000 \\
(0.024)\end{array}$ \\
\hline Post-ITS (5) & $\begin{array}{l}-0.035^{*} \\
(0.018)\end{array}$ & $\begin{array}{l}-0.032^{*} \\
(0.018)\end{array}$ & $\begin{array}{l}-0.008 \\
(0.025)\end{array}$ \\
\hline Post-ITS (6) & $\begin{array}{c}-0.058^{* * *} \\
(0.022)\end{array}$ & $\begin{array}{c}-0.056^{* * * *} \\
(0.021)\end{array}$ & $\begin{array}{c}0.007 \\
(0.030)\end{array}$ \\
\hline Post-ITS (7) & $\begin{array}{c}-0.063^{* * *} \\
(0.024)\end{array}$ & $\begin{array}{c}-0.057^{* *} \\
(0.023)\end{array}$ & $\begin{array}{c}0.013 \\
(0.034)\end{array}$ \\
\hline Post-ITS (8) & $\begin{array}{c}-0.075^{* * *} \\
(0.026)\end{array}$ & $\begin{array}{c}-0.068^{* * *} * \\
(0.025)\end{array}$ & $\begin{array}{c}0.015 \\
(0.034)\end{array}$ \\
\hline Post-ITS (9) & $\begin{array}{c}-0.072 * * \\
(0.030)\end{array}$ & $\begin{array}{c}-0.063 * * \\
(0.028)\end{array}$ & $\begin{array}{c}0.030 \\
(0.039)\end{array}$ \\
\hline Post-ITS $(>=10)$ & $\begin{array}{c}-0.092^{* *} \\
(0.037)\end{array}$ & $\begin{array}{c}-0.086^{* *} \\
(0.036)\end{array}$ & $\begin{array}{l}-0.011 \\
(0.040)\end{array}$ \\
\hline$\#$ of Observations & 2,079 & 2,079 & 2,079 \\
\hline \# of MSAs & 99 & 99 & 99 \\
\hline Adj. R-squared & 0.956 & 0.955 & 0.986 \\
\hline
\end{tabular}

Figure 3A.

Effects of 511 Systems adoption on COST (congestion cost) over years

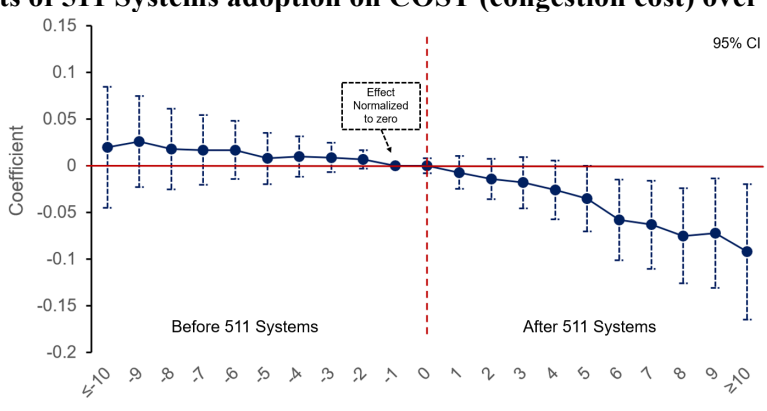

Weeks relative to 511
Systems adoption

Effects of 511 Systems adoption on TIME (delay hours) over years

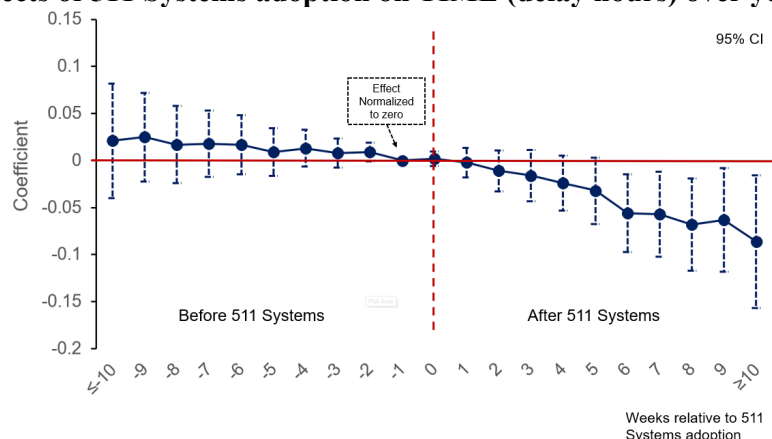

Figure 3C.

Effects of 511 Systems adoption on VMT (traffic volume) over years

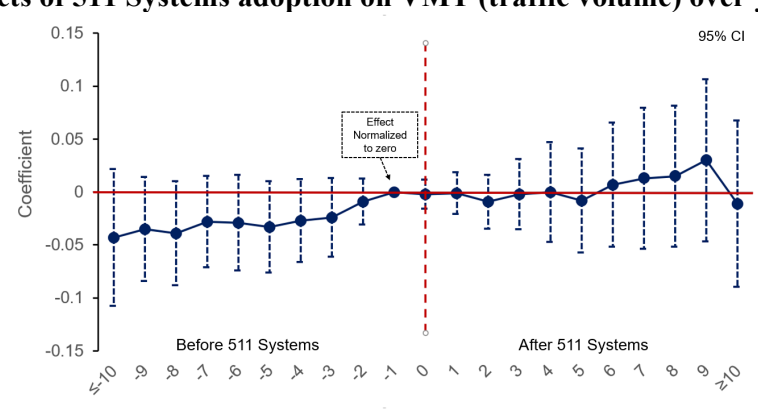

Weeks relativiv to 511
Systems adooftion 
assume different trends in traffic congestion in MSAs that adopted and did not adopt 511 Systems. To rule out this possibility, we execute the leads-and-lags model proposed by Autor (2003). Specifically, we incorporate pre-adoption and post-adoption dummies into our DID model to capture inter-temporal effects:

$$
\operatorname{CONGESTION}_{i t}=\sum_{j} \tau_{j} \operatorname{PreITS}_{i t}(j)+\beta \text { ITS }_{i t}+\sum_{k} \omega_{k} \operatorname{PostITS}_{i t}(k)+\gamma X_{i t}+u_{i}+v_{t}+\varepsilon_{i t}
$$

$\operatorname{PreITS}_{i t}(j)$ and $\operatorname{PostITS}_{i t}(k)$ are pre-treatment placebos and post-treatment variables, which are equal to 1 if the temporal distance between the year $t$ and the year that 511 Systems are adopted by MSA $i$ are $j$ (or $k$ ) years. Intuitively, this model allows us to capture the trend of traffic congestion and to observe the relative effects before and after the treatment on an annual basis.

Results are shown in Table 6 and Figure 3. We find no significant difference in traffic congestion between treated and untreated MSAs before the adoption (i.e. $\operatorname{PreITS}_{i t}(j)$ are not significant for $j \leq-10$ to $j=-2$ ), supporting the parallel trends assumption and validating our DID estimates. We also observe a significant decrease in congestion cost and time 5 years after the 511 Systems adoption, and such negative relative effects remain statistically significant until the end of our timeframe. This demonstrates compelling evidence that the congestion-mitigating effects of ITS persist and grow after their implementation.

\section{Robustness, Sensitivity, and Falsification Checks}

Having identified the congestion-mitigating effect of 511 Systems, we next subject our baseline analysis to several robustness, sensitivity, and falsification checks.

\subsection{Determinants of 511 Systems Adoption}

One concern is a potentially endogenous adoption of 511 Systems. While the results from leads and lags models do not suggest heterogeneity in pre-treatment congestion trend, it is possible that there is stable variation in congestion across treated and untreated MSAs. Specifically, a reverse causality concern may be possible. We first use simple t-statistics to compare the congestion status and traffic volumes between treated and untreated MSAs in 1998, 1999, and 2000 before any U.S. states or cities adopted 511 Systems. In Table C1 in Appendix C, we find that while MSAs that later adopted 511 Systems had, on average, higher congestion costs and delay hours than untreated MSAs did, such differences are not statistically significant conditional on the covariates (e.g., population) we accounted for in the main DID estimation. 
Second, given the staggered pattern of 511 Systems adoption across locations and times, we systematically assess the determinants of 511 Systems adoption by leveraging our panel dataset. Specifically, we use a discrete-time hazard model (Jenkins 1995) to predict 511 Systems adoption as a function of MSA-level demographics, socio-economic factors, transportation-related factors (i.e., public transit, commercial traffic), and past congestion status. We measure past congestion levels using lagged traffic congestion (COST and TIME) for one, two, and three years. In Table C2, we find while population and unemployment are significant predictors, past congestion status does not significantly determine 511 Systems adoption, implying that simultaneity between ITS and traffic congestion may not be a concern.

\subsection{Instrumental Variable Analysis: Historical Routes within Cities}

Next, we further address a concern that ITS may be adopted by MSAs in response to contemporaneous shocks to traffic by utilizing an alternative identification strategy. Specifically, we conduct instrumental variable analysis with two IVs about historical routes within MSAs: railroad route miles in 1898 and major road expansions between 1835 and 1850. We choose these IVs for three reasons: First, both IVs are strong predictors for current road networks, throughout which the 511 Systems were installed (i.e., the independent variable of interest), and these IVs that characterize the U.S. historical road systems more than a century ago are unlikely to correlate with contemporaneous congestion status in 1994-2014. Second, even if there might exist confounders correlated with both historical routes and current congestion, we already account for their effects using a rich set of time-varying covariates, MSA-specific factors, and year-specific trends, strengthening the validity of the IVs. Third, these IVs are commonly-used in the transportation economics (Duranton and Turner 2011). Baum-Snow (2007), Michaels (2008), and Duranton and Turner (2011) also use historical routes as valid IVs for features of the interstate road system. We use Duranton and Turner (2011)'s data for the historical routes to execute a 2SLS estimation. Results shown in Table C3 indicate qualitatively similar estimates with our baseline ones. The post-estimation diagnostic tests support that the IVs are not weak (KP F-test) and are exogenous (Hansen $J$ test). In sum, the congestion-mitigating effects of 511 Systems remain robust in the IV analysis.

\subsection{Sample Selection}


Another concern is that our estimation may be sensitive to the selection of MSAs in our sample. To check this possibility, we conduct a series of subsample analyses. First, we consider the complexity introduced by MSAs that span across states. Technically, cross-state MSAs are less comparable to intra-state ones since the former are more complex with respect to transportation mixtures and congestion status of neighboring states. Therefore, we exclude 22 cross-state MSAs and check if our estimation is sensitive to sampling. Second, we consider whether the decision of 511 Systems adoption is made by a state or a city government. Such decision types and corresponding implementation processes may introduce heterogeneity that possibly biases our estimation. We accordingly conduct two distinct analyses, one that is restricted to MSAs where state governments decided to adopt 511 Systems, and the other is about California MSAs where local governments made 511 decisions. Last, we consider temporal heterogeneity in our sample timeframe. It is noteworthy that traffic congestion had dropped after Financial Crisis in 2009. While year fixed-effects account for this nationwide event, the impacts of 511 might differ across time and MSAs and may drive down traffic congestion in the post-Financial Crisis period. Thus, we exclude this period and restrict our sample to 1994-2008. Using the subsample until 2008 also avoids some noises from the prevalent usage of navigation apps after 2009. For example, Google Maps has gained popularity since 2009 when it started to provide real-time traffic information by crowd-sourcing GPS data from cellphones. Table C4 reports the results from subsample analyses and indicates that our main findings remain robust.

In addition to analysis on the sampled MSAs, we also examine the generalizable potential of our estimates to other MSAs in the U.S. ${ }^{19}$ Following extant transportation studies (e.g., Couture et al. 2018), we compare the statistics of individual trip and aggregate traffic between our in-sample MSAs $(\mathrm{N}=99)$ and out-of-sample MSAs (N=191) prior to the adoption of 511 Systems (separately in 1995 and 2001). ${ }^{20}$ In Table C5-1, we find that individual trip statistics do not significantly differ between in-sample and out-ofsample MSAs. Moreover, while aggregate traffic statistics (i.e., daily vehicle miles traveled and vehicle

\footnotetext{
${ }^{19}$ Recall that the main analyses build on the 99-MSA sample due to the availability of congestion data in the AUMS dataset.

${ }^{20}$ National Household Travel Survey (NHTS) provides individual trip statistics aggregated to an MSA, including mean trip distance, mean trip duration, mean trip speed and mean trip number per driver on a random day. HPMS and Census provide MSA-level traffic statistics, including mean daily vehicle miles traveled and mean daily vehicle miles traveled.
} 
travel time) of in-sample MSAs are larger than that of out-of-sample MSAs, the differences are not statistically significant conditional on the covariates in Table 3 . We conduct a similar analysis that compares treated and untreated MSAs in both in-sample and out-of-sample (Table C5-2) and obtain a similar result.

In sum, the findings suggest that the sampled MSAs do not differ much from other MSAs on individual travel and aggregate traffic statistics conditional on observables, and we have confidence to extrapolate the identified effects of 511 Systems to elsewhere in the U.S.

\subsection{Coarsened Exact Matching}

The next concern is that while there is little heterogeneity between treated and untreated MSAs conditional on time-varying covariates and fixed effects, it is possible that untreated MSAs are not a representative counterfactual for (or not as good as comparable to) treated MSAs. To remedy this, we execute a Coarsened Exact Matching (CEM) procedure to limit the pre-treatment differences between the treated and untreated MSAs (Blackwell et al. 2009). In doing so, we match them based on several criteria: population, unemployment rates, lagged road miles, and traffic volumes. The CEM procedure generates a weight for balancing the heterogeneity across treated and untreated MSAs. Replicating DID regressions using the weight, we find estimates adjusted by CEM are qualitatively similar to our main results (See Table C6).

\subsection{Random Implementation (Shuffle) Tests}

A common concern for the DID estimation is a possibility of false significance due to spurious relationships or serial correlations in our dependent variables. While we cluster standard errors within MSAs for the baseline estimation, it is useful to implement a falsification test suggested by Bertrand et al. (2004). Following extant literature (e.g., Greenwood and Wattal 2017), we execute a random implementation test by randomly generating and assigning dichotomous pseudo (or placebo) treatments to each MSAs. Using the pseudo indicator, we run our baseline regressions, stored the estimates, and replicated the procedure for 1,000 times. This test allows us to identify more cleanly if the correlation within MSA-year is unaccounted for and to check if our observed effect is merely driven by outliers. Table $\mathrm{C} 7$ and Figure $\mathrm{C} 1$ show the results. Comparing the estimate using ITS with that using pseudo treatments as independent variables, the probability that the congestion-mitigating effect of 511 Systems appears purely by chance is significantly 
low. Furthermore, the placebo coefficients are not significantly different from zero, suggesting that autocorrelation might not be a serious issue.

\subsection{Measure Operationalization}

Another concern is that the estimation may be sensitive to our measurements. To mitigate the possibility, we first utilize alternative measures of CONGESTION - FUEL and $\mathrm{CO}_{2}$ - and replicate the DID estimation. We observe a similar decrease in fuel consumption and $\mathrm{CO}_{2}$ emission due to congestion after 511 Systems adoption (Table 5, Columns 3 and 4), which is translated into annual savings of 53 million gallons of fuel and 10 billion pounds of $\mathrm{CO}_{2}$ emission for the U.S. urban areas. In addition, we also use MSA-level aggregate congestion measures (i.e., total congestion cost, excessive time, fuel, and $\mathrm{CO}_{2}$ ), instead of average congestion per commuter, as dependent variables. The results remain consistent (Table C8)

Second, we vary the measure for ITS. Per extant platform-entry studies (e.g., Chan and Ghose 2014), we label those MSAs that implemented 511 Systems in the $4^{\text {th }}$ quarter of the year (i.e., October to December) as if they adopt them in the following year, given that 511 Systems need time to materialize their impacts on traffic congestion, which may likely be manifested in the next year's statistics. We also use an alternative weight—area-size proportional to each state — to construct the ITS measure for cross-state MSAs (e.g., New York-Newark NY-NJ-CT). The estimates using different ITS measures remain consistent (Table C9).

\subsection{Traffic Applications Developed in the Private Sector}

Recently, technology companies have developed commercial traffic applications (e.g., Google Maps) that became popular among drivers, thanks to the proliferation of mobile devices. Commuters use these applications to obtain real-time traffic information and plan their travels. While our study focuses on 511 Systems that have worked for both commuters and local governments for a long period of time (since 2001) prior to the prevalence of Google Maps (after 2009), we study the role of Google Maps in traffic congestion for the purpose of generalizability (Cheng et al. 2016). ${ }^{21}$ While the Google Maps usage data are not publicly available, we obtain the search popularity of the term "Google Maps" from Google Trends as a proxy, and we use it as an independent variable and replicate the baseline estimation. Results are shown in Table C10

\footnotetext{
${ }^{21}$ Note that the baseline DID model has already accounted for the availability of Google Maps by year fixed-effects because the initial launch and following updates of Google Maps in the US are one-time events for all Internet users regardless of locations. This means the congestion-mitigating effect of 511 Systems still holds conditional on the availability of Google Maps service (and any other Internet-based navigation applications that were launched and updated in the same fashion).
} 
in Appendix C. First, we observe that the search intensity of Google Maps is associated with a decrease in excessive travel time, similar to our findings from the 511 Systems. This reinforces our theoretical claim that real-time information provision helps to alleviate traffic congestion. Also, the effects of 511 Systems adoption are still significant conditional on the Google Maps usage across locations and times. Finally and importantly, 511 Systems and Google Maps usage complement to each other in reducing traffic congestion.

\section{Congestion-Mitigating Mechanisms}

While we have shown consistent evidence of 511 Systems on mitigating traffic congestion, it is important to understand the underlying mechanisms. Accordingly, we empirically examine such questions: (i) How do ITS affect individual travel behavior? (ii) How do ITS interact with conventional traffic interventions?

\subsection{Managing Traffic Demand - Changes in Travel Decision-Making and Travel Behavior Patterns}

To understand the role of ITS in the traffic demand side, we examine how ITS help commuters to adjust their travel preferences and driving behavior patterns and to alter the traffic demand patterns over time.

\subsubsection{Commute to Work: Travel Time, Departure Timing, and Transportation Modal Choice}

Traffic demand changes led by ITS might be largely manifested in work-trip behaviors. With traffic information from ITS, commuters can optimize travel decisions on their departure times and transportation modes to save their travel time to work. These work-trip adjustments represent a more efficient use of the transportation infrastructures (e.g., roads, railways), thereby easing traffic congestion. To empirically test this mechanism, we collect individual-level data from ACS Public Use Microdata Samples (ACS PUMS) for $2000-2014^{22}$ on work-trip features, including "travel time to work," "means of transportation to work," and "time of departure for work - hour and minute" as well as personal information (e.g., personal income, employment status). We match the ACS PUMS data to our main dataset to study how the adoption of 511 Systems affects individual travel decisions across locations and over time.

First, we focus on changes in travel time of individual drivers after ITS adoption because the most direct implication of ITS is travel time. While we provide evidence that 511 Systems help to mitigate travel delays at the aggregate MSA level, it is useful to assess travel time changes at the level of individual drivers.

\footnotetext{
${ }^{22}$ The American Community Survey (ACS) is the largest ongoing nationwide survey by the U.S. Census Bureau, collecting household and personal information from 3.5 million people ( $1 \%$ of the U.S. population) annually.
} 
Thus, we replace CONGESTION with Travel Time to Work as the dependent variable and replicate the baseline estimation. Table D1 in Appendix D reports the results. We find that the adoption of 511 Systems significantly reduces travel time for drivers whose commuting time are within 60 minutes. Moreover, this effect is significantly larger for drivers who commute in heavy-traffic rush hours (7-10 am; 5-8 pm). This corroborates our main results and demonstrates that ITS inform commuters and save their travel time.

Second, we examine departure time choices, an important element of the travel decision-making if peak-hour speed is of concern (Small and Verhoef 2007). We expect that, based on traffic information from ITS, commuters can better optimize their departure timing to work in order to avoid traffic congestion. To test this proposition, we examine the impact of 511 Systems adoption on the decisions of departing to work in the heavy-traffic hours or light-traffic ones. Table D2 shows that drivers in locations that adopted 511 Systems are less likely to depart in heavy-traffic hours. This supports our proposition that ITS help commuters to make more informed travel decisions regarding departure timing to avoid traffic congestion.

Finally, we consider transportation mode choices (e.g., Train 1980, Arnott 2001), another important work-trip decision by commuters who seek to minimize their travel costs. Like optimizing departure timing, a better modal choice could also be effective in alleviating traffic congestion (Arnott and Small 1994). To estimate the impact of ITS on work-trip transportation mode choices, we use the ACS PUMS data on the means of transportation modes to work (e.g., private car, taxi, public transit, bicycle, or walking). We use a dichotomous choice for each mode as a dependent variable, and we replicate the baseline specification. Table D3 shows interesting evidence that, with 511 Systems, fewer commuters choose to travel to work by car, taxi, and bus, transportation modes, which extensively occupy roads and exacerbate traffic congestion; while more commuters use rail-based transit, walking, or biking, which are more environmentally-friendly. These findings support our proposition that ITS better inform individual drivers and facilitate the distribution of traffic demand across transportation modes (e.g., Mogridge 1997, Anderson 2014).

\subsubsection{Frequency and Distance of Daily Travel}

Next, beyond work-home travel decisions, we study how ITS change the general pattern of individual daily trips. We expect that, with transparent traffic information provided by ITS, drivers is able to schedule their 
travels more efficiently and reduce unnecessary trips with excess travel time. To test this, we retrieve census-tract level data on daily personal trips from NHTS. The latest two NHTS datasets provide travel information in 2001 and 2009-2011, respectively. These datasets show that while the number of family members and private-owned vehicles per household had increased from 2000 to 2011, the average trip distance had dropped significantly from 81.8 miles in 2000 to 63.3 miles in 2011 . We match this censustract-level trip data to the main dataset to study daily trip frequencies and distances before and after the 511 Systems adoption. Table D4 shows that in the census tracts of MSAs with 511 Systems, the average number of daily vehicle trips and vehicle mileages are lower by $1.6 \%$ and $4.9 \%$, respectively, than those in untreated census tracts. This implies that information provided by ITS help individual drivers to reduce unnecessary personal and household travels, corroborating our theoretical proposition on the informative role of ITS.

\subsubsection{Travel Time Uncertainty}

Traffic congestion is often accompanied by travel time uncertainty (Becker 1965). The transportation economics literature posits that the absence of sufficient information increases travel time uncertainty, expected cost of commuting, and variability of queueing patterns, all of which cause traffic congestion (Small and Verhoef 2007). Hence, uncertainty in travel time can be reduced when drivers are better informed about the traffic conditions (Noland 1997). We examine if information provided by ITS reduces travel time uncertainty. Arguably, a major source of travel time uncertainty is extra travel time due to congestion. Thus, we measure this uncertainty using a deviation of the proportion $\left(\mathrm{Z}_{\mathrm{it}}\right)$ of excess time to free-flow travel time. We use Travel Time Index (TTI) and Commuter Stress Index (CSI) in the AUMS dataset to construct the uncertainty measure. TTI is calculated by the total travel time divided by free-flow travel time. TTI includes travels in all directions in the peak periods, while CSI only includes travels in peak directions. Based on TTI and CSI, we construct the travel time uncertainty measure $\left(\mathrm{U}_{\mathrm{it}}\right)$ as follows:

$$
U_{i t}=\frac{\left|Z_{i t}-\frac{1}{t_{0}} \Sigma_{1}^{t_{0}} Z_{i t}\right|}{\sigma_{Z_{i t_{0}}}}, t_{0}=\left\{\begin{array}{c}
T_{0}-1994, \text { if } 1994 \leq t<T_{0} \\
2014-T_{0}, \text { if } T_{0}<t \leq 2014
\end{array}, Z_{i t}=T T I_{i t}\left(\text { or } C S I_{i t}\right)-1\right.
$$

Where $i$ and $t$ indicate MSA and year, respectively; $T_{0}$ is the year of 511 Systems adoption for an MSA, and $t_{0}$ is the number of years since 511 Systems have been adopted or during which they have not been 
adopted. $\sigma_{Z_{i t_{0}}}$ is the standard deviation of $Z_{i}$ in the period of $t_{0}$. We use $U_{i}$ as the dependent variable derived from TTI and CSI and replicate the baseline DID regressions. Table D5 reports the results. We find that the average travel time became less uncertain after 511 Systems adopted, thus supporting our proposition.

\subsubsection{Navigation Route Choices}

Finally, we consider changes in navigation route choices as an important demand-side mechanism of ITS. As route choice is a travel decision that can be improved by better information (e.g., Ben-Akiva et al. 1991), we examine how ITS affect route choices by evaluating traffic allocation within existing road networks. Utilizing the HPMS data, we assess three classes of roads - highways, major roads, and local roads. ${ }^{23}$ Empirically, we use traffic shares in each of these road types as dependent variables to examine how the 511 Systems alter traffic allocation among these roads. Table D6 reports the results. We find that the adoption of 511 Systems is significantly associated with a decrease in the traffic share of major roads. Major roads are the most congested road type, and the reduction in traffic volume on major roads after the 511 Systems adoption explains the congestion-mitigating effect of ITS. Moreover, 511 Systems are not significantly associated with traffic shares in highways and local roads, possibly because these roads accommodate more traffic diverted from major roads. These findings suggest that ITS inform drivers to optimize route choices, allocating traffic and reducing congestion more efficiently (Ben-Akiva et al. 1991).

In sum, we find that commuters benefit from the information provided by ITS to better schedule their trips, reduce unnecessary daily travels, mitigate travel time uncertainty, and optimize their navigation routes. Notably, not only do ITS allow a commuter to choose alternative transportation modes or driving times that increases her utility, but also getting her off from congested roads saves other commuters' travel time on the roads. To wit, this concludes that ITS improve the demand-side collective welfare.

\subsection{Managing Traffic Supply -ITS and Conventional Traffic Interventions}

To test how ITS enhance traffic supply management, we study how the impact of ITS is affected by conventional interventions - road supply adjustment and public transit services (Arnott and Small 1994).

\subsubsection{ITS and Road Supply}

\footnotetext{
${ }^{23}$ Highway is a measure by grouping "interstate highway" and "expressway/freeway", while Major Road is by aggregating "principal/minor arterial" and "major/minor collector".
} 
First, we assess the interaction of ITS and road supply on traffic congestion. While the "Fundamental Law of Road Congestion" (Duranton and Turner 2011) suggests that solely increasing road supply does not reduce traffic, we argue that ITS help local governments to adjust the road supply towards better allocating traffic and mitigating congestion. Table D7 reports the results from the interaction effect of ITS and road supply. First, we find that road expansion exacerbates traffic congestion, consistent with extant transportation economics studies (e.g., Goodwin 1996, Duranton and Turner 2011). More importantly, the induced traffic by road expansion is attenuated by ITS. This beneficial effect of ITS is consistent with anecdotal evidence (Government Technology 2011b) that New York City reduced traffic congestion in 2009 by utilizing the taxi GPS data to identify congested roads, block them, and distribute traffic effectively. This finding suggests that the impact of ITS on traffic congestion depends on the existing physical transportation infrastructures, and while increasing road supply can make traffic congestion worse, the adoption of ITS could ameliorate such an adverse effect.

\subsubsection{ITS and Public Transit Services}

To further explore the joint effects of ITS and other traffic interventions, we examine the joint impact of ITS and public transit services on traffic congestion. Public transit has attracted strong public support recently, especially in dense metropolitan areas (e.g., Los Angeles, New York City, Seattle), due to its capability to absorb flocks of commuters in peak hours (Anderson 2014). We incorporate public transit services into our empirical assessment, focusing on two distinct service types - bus and rail. The former competes with private cars and trucks for limited road space, while the latter eases the burden of road transportation. Following extant transportation economics literature (e.g., Duranton and Turner 2011), public transit service is measured by the number of Vehicles Operated for Maximum Services (VOMS) for both bus and rail using the National Transit Data (NTD). Using these measures, we test the effect of public transit services and its joint effects with ITS on traffic congestion in urban areas.

Table D8 reports the results. Interestingly, ITS decrease traffic congestion to a greater degree in MSAs with larger rail networks, but it is not the case in MSAs with more bus services. These findings illustrate that traffic congestion is relieved to a greater extent when ITS lead more commuters to utilize rail transits 
rather than buses in already traffic-heavy conditions. This is consistent with our finding that ITS could guide commuters to optimize their transportation mode (Table D3). More importantly, these findings also suggest that ITS help local governments to improve public transit, especially rail transportation, to accommodate more traffic and mitigate congestion. ${ }^{24}$ The above evidence implies that local transportation agencies leverage ITS to coordinate traffic management with public transit services to ease congestion.

\section{Empirical Extensions on ITS Use}

While thus far we have provided a range of evidence on the impact of ITS on traffic congestion and its underlying mechanisms, the main analyses have yet to show how the use of ITS by commuters and governments affects traffic congestion. It is important to understand the impact of not only ITS adoption but also the extent of ITS use on traffic congestion, which would offer more practical implications for ITS stakeholders, such as which functionalities of ITS to implement. While empirical data on IT use is limited, we extend our empirical investigation with a few measures of ITS use.

First, we assess the effect of IT use on traffic congestion using the number of 511 calls and website visits. It is empirically challenging because only a few states report relevant statistics for limited years in our study timeframe. We found data that contains 511 calls and website visits from Florida, Iowa, Kentucky, and Utah in 2010-2014. Thus, we classified 11 MSAs in these states (listed under Table E1) into a treated group and MSAs that have never adopted 511 Systems into a control group, and we then replicate the DID estimation. The results are shown in Table E1 in Appendix E. We find that the number of 511 website visits is associated with a significant decrease in traffic congestion, while the effect of 511 calls is not significant.

Second, we study the effect of ITS functionalities that each state incorporates into their 511 Systems. While 511 Deployment Coalition requires consistency in the adoption of 511 Systems, a few variations in implemented functionalities exist across states. We retrieve the functionality data from a report, titled “Implementation and Operational Guidelines for 511 Services", published by 511 Deployment Coalition. The functionalities include which information (e.g., about road condition, congestion status) each state 511

\footnotetext{
${ }^{24}$ For instance, similar to 511 Systems, ITS programs under the CIVITAS initiative are adopted by over 80 European cities for sustainable traffic mobility. By monitoring, collecting, and analyzing real-time traffic information, innovative ITS projects provide solutions for public transport enhancement, including fleet management, to optimize routing and schedule for buses and trams.
} 
System made available to the public and through which channels (i.e., roadside variable message signs and 511 websites with interactive traffic maps). We interact these functionalities with ITS to examine the incremental effect of adding these functionalities to 511 Systems on traffic congestion. The results are shown in Table E2. We find that 511 Systems show a greater impact when road condition, congestion, and travel time information are provided. In addition, the marginal value of incorporating a 511 website is larger than roadside variable message signs. The findings not only support that information provision is critical to ease traffic congestion but also stress the relative effectiveness of information provision ahead of travels (via 511 websites) versus that during travels (via roadside variable message signs).

Third, we explore another proxy for ITS use by examining the federal funding of 511 Systems across locations and years. ${ }^{25}$ Following extant organizational studies (e.g., Brynjolfsson and Hitt 2003), we use the amount of monetary investments in 511 Systems with federal aids to measure the degree and sophistication of ITS implementation. This is because additional funding is likely to allow states to develop more advanced ITS (e.g., Pang et al. 2016). We retrieve funding data for 511 Systems from the Federal Aid Archive and matched them to our main dataset. We replicate the DID estimation using the amount of federal funding for ITS as an independent variable. Table E3 shows that 511 Systems implemented with larger federal subsidies have a greater impact on traffic congestion.

Lastly, the impact of ITS use may depend on the contexts in which ITS are implemented. In particular, we explore how the effects of 511 Systems vary by population size and congestion severity. We expect that ITS is more heavily used in MSAs with larger population or with severer congestion. For population size, we create four dummy variables - very large MSAs (more than 3 million), large MSAs (1 million to 3 million), medium MSAs (500,000 to 1 million), and small MSAs (less than 500,000) - following the classification by the AUMS dataset. We then interact these variables with the ITS variable and replicate our estimation. Table E4 shows that the impact of 511 Systems in traffic congestion is more pronounced in

\footnotetext{
${ }^{25}$ While the funding process for ITS could be affected by past congestion status, we argue that our previous analyses mitigate such a possibility: (i) We find that past congestion status does not determine the adoption timing (thus grant effective date) of 511 Systems (see Table C2); (ii) In all specifications, we account for location-related idiosyncrasies using time-varying variables as well as location and time fixed-effects; (iii) With the instrumental variables (IVs) that are not correlated to contemporary confounders such as the funding process, we still see the consistent estimates of 511 Systems (see Table C3).
} 
the large and the very large MSAs than in the small ones. Next, we assess the effects of 511 Systems at different congestion severity quantiles across MSAs. This allows us to understand how the effectiveness of ITS varies depending on congestion conditions. From Table E5, we find that the congestion-heavier MSAs benefit more from the 511 Systems adoption than congestion-lighter ones in saving travel time and costs.

\section{Discussion}

\subsection{Key Findings}

In this study, we investigate the role of ITS in alleviating traffic congestion and quantify this effect by focusing on 511 Systems, the largest federally-supported ITS program in U.S. urban areas. While policymakers hope that ITS can be a viable solution to traffic management, our understanding of whether and how ITS can mitigate traffic congestion is limited. To fill this significant gap in research and practice, we compile a unique panel dataset of 99 U.S. urban areas over 21 years to empirically assess the effectiveness of ITS in mitigating traffic congestion. To our knowledge, this study is the first effort to theorize and quantify the roles of ITS in mitigating traffic congestion. We find that the adoption of 511 Systems is associated with a decrease in traffic congestion, an effect that amounts to an annual saving of $\$ 4.72$ billion in congestion costs, 175 million hours of travel time, 53 million gallons of fossil fuel energy, and 10 billion pounds of $\mathrm{CO}_{2}$ emissions. We also show ITS to help commuters to schedule travel more efficiently, choose better navigation routes, and optimize transportation mode. In addition, we offer evidence that the informational functionalities and the usage level of 511 Systems are significantly associated with a decrease traffic congestion. Our findings are consistent with our theoretical proposition that ITS inform drivers to make better decisions in their daily commutes and inform local governments to develop an urban traffic management capability to effectively mitigate congestion.

\subsection{Theoretical Contributions}

This study makes several key contributions to both the IS and the transportation economics literatures. First, we contribute to the emerging literature on the societal impacts of IT by theorizing the IT-enabled traffic management capability in mitigating traffic congestion, a notorious societal problem in most developed and developing nations. Specifically, we quantify the significant economic and societal impact of ITS. The extant work on the societal impact of IT has paid limited attention to transportation. Although a few recent 
studies started to identify the societal impact of the sharing economy (e.g., Greenwood and Wattal 2017, Ge et al. 2016), these studies have not discussed IT-enabled capabilities for local governments. Our study closes this gap by theorizing how IT helps local governments to develop effective traffic management.

Second, we contribute to the IT capability literature by offering new insight on how ITS enable governments to develop traffic management capabilities. The IS literature has examined IT capabilities mostly in the private sector (e.g., Pavlou and El Sawy 2006, Rai et al. 2012), whereas we draw upon and extend this literature to the public sector (Pang et al. 2014a). We argue that local governments can utilize information provided by ITS to develop a traffic management capability. To support this proposition, we show suggestive evidence that congestion-mitigating roles of ITS materialize in both the demand and the supply side of traffic management. Moreover, we contribute to the Green IT literature (Malhotra et al. 2013) by responding to the call to research on the role of IT in environmental sustainability (Melville 2010). We show that ITS save fossil fuel and reduce $\mathrm{CO}_{2}$ emissions by easing traffic congestion.

Third, we contribute to the transportation economics literature (e.g., Goodwin 1996, Cervero 2002, Arnott 2001, Wachs 2002, Small and Verhoef 2007) by offering empirical evidence that IT-enabled traffic interventions are effective in mitigating traffic congestion. Moreover, by examining the effect of ITS on traffic volume at the census-tract level, we show that ITS can even decrease the number of daily trips and travel distance (Table D4). Our finding that ITS help drivers to make more informed decisions in routes, timings, and transportation modes complements extant transportation economics studies on information provision and traffic congestion (Arnott et al. 1991, Emmerink et al. 1996). These studies have used analytical modeling and simulation and set up a theoretical tension as to whether the information provided by driver navigation systems is welfare-inducing or welfare-reducing (Noland 1997). We show evidence to reconcile this tension by demonstrating the welfare-inducing role of ITS in mitigating traffic congestion.

\subsection{Practical Implications}

This study provides policy implications for (1) transportation policymakers and urban planners, and (2) individual commuters and drivers. First, for transportation policymakers, we show that ITS could be a more cost-effective means to address traffic problems than costly physical transportation infrastructure. Our 
estimation shows $\$ 4.72$ billion annual cost savings for U.S. urban areas thanks to the 511 Systems adoption, while the total investments in 511 Systems over 10 years are only $\$ 135$ million. More importantly, our study suggests that urban planners pay more attention to the potential of IT (Wachs 2002, Glaeser 2011) in transportation. Within government agencies, IT has been shown to improve administrative efficiency (Pang et al. 2014b). However, its potential to create social welfare by tackling societal issues needs to be more recognized by city planners and policymakers. We hope our study is a modest step toward this direction.

Second, this study has practical implications for individual drivers and daily commuters. When drivers anticipate traffic congestion, they are better off accessing information provided by ITS to schedule their travel plan more wisely, adjust their departure times, and reduce travel time uncertainty on the road. Moreover, by checking traffic information from ITS, commuters could consider alternative transportation modes (e.g., rail-based public transit) and optimize their navigation routes to avoid traffic congestion during work-trip commuting, especially in rush hours (Arnott and Small 1994).

\subsection{Limitations}

This study has several limitations. First, we do not have complete congestion data for all MSAs due to data availability. The AUMS dataset only covers congestion data for 101 metropolitan areas. Nonetheless, we find that individual travel and aggregate traffic patterns do not differ significantly between in-sample and out-of-sample MSAs, conditional on observed heterogeneities (Section 6.3). Nevertheless, we still encourage further research efforts in collecting more fine-grained congestion data from more urban areas in the U.S. and other countries to improve the estimates of our study and generalize our findings.

Second, while we seek to rule out as many confounds and alternative plausible explanations as possible, our identification strategy does not rely on an ideal randomized controlled experiment. Thus, there might still be unaccounted factors that could bias our estimates. For example, although state governments implement standardized 511 Systems, how local governments use these systems may vary. Likewise, for drivers, the actual usage of 511 Systems may differ across MSAs. While we provide suggestive evidence on the use of ITS by examining the effect of 511 Systems functionalities, number of 511 calls, and website visits (Section 8), we are conservative about the findings and encourage follow-up research along this line. 
Finally, while our main analysis, supported by a series of robustness checks, aims to carefully uncover the effect of ITS on traffic congestion, some of the underlying mechanisms have not been fully examined. These include development of traffic management capabilities and the relative effectiveness of trip planning (ahead of travels) versus trip coordination (during travels). We cannot fully cover these directions due to empirical challenges in obtaining available, reliable, and comprehensive administrative data and measuring IT-leveraging traffic management capabilities at the city level. We encourage future work to advance our theoretical explanations with additional and rich empirical evidence.

\section{Concluding Remark}

This study represents one of the first attempts to theoretically develop and empirically assess the impact of IT-enabled interventions on traffic congestion by examining the deployment of 511 Systems, the largest federally-supported ITS program in the U.S. To the best of our knowledge, traffic congestion and its economic and environmental impacts are major societal problems that have seldom been examined in the IS literature. Our study highlights the importance of IT in a broader economic and societal setting and identifies a new and promising avenue for IS research on how IT can improve the quality of life and create public value by tackling chronic urban problems, such as traffic congestion. Future research can examine how ITS enhance traffic mobility and safety, how to facilitate the development of traffic management capabilities for local governments, and how to design effective transportation technologies. We hope our study sparks a new intellectual discourse around IT and transportation in the IS discipline.

\section{Acknowledgements}

We would like to thank the senior editor, the associate editor, and the anonymous reviewers whose insights significantly improved the quality of this work. This study also benefitted from the seminar and conference participants at the London School of Economics, Erasmus University, Nanyang Technological University, Chinese University of Hong Kong, the International Conference on Information Systems (ICIS), the Conference on Information Systems and Technology (CIST), and the Erasmus Energy Forum. Furthermore, we would like to thank the Temple MIS Department as well as Jing Gong, Brad N. Greenwood, Ting Li, Sunil Wattal, and Youngjin Yoo, for comments on earlier versions of this work. The research was partially funded by the Young Scholars Forum at Fox School of Business. All remaining errors are our own. 


\section{References}

2015 Annual Urban Mobility Scorecard. https://mobility.tamu.edu/ums/, retrieved on April 16, 2018. Anderson ML (2014) Subways, strikes, and slowdowns: The impacts of public transit on traffic congestion. The American Economic Review 104(9):2763-2796.

Angrist JD, Pischke JS (2008) Mostly harmless econometrics: An empiricist's companion (Princeton University Press).

Arnott R (2001) The economic theory of urban traffic congestion: a microscopic research agenda. Workshop on Environmental Economics and the Economics of Congestion: Coping with Externalities, Venice International University, Venice Summer Institute, San Servolo, Italy.

Arnott R, De Palma A, Lindsey R (1991) Does providing proto drivers reduce traffic congestion? Transportation Research Part A: General 25(5):309-318.

Arnott R, Small K (1994) The economics of traffic congestion. American Scientist 82(5):446-455.

Auer A, Feese S, and Lockwood S (2016) History of Intelligent Transportation Systems. Intelligent Transportation Systems Joint Program Office, U.S. Department of Transportation. Report number: FHWA-JPO-16-329.

Autor DH (2003) Outsourcing at will: The contribution of unjust dismissal doctrine to the growth of employment outsourcing. Journal of labor economics 21(1):1-42.

Barth M, Boriboonsomsin K (2008) Real-world carbon dioxide impacts of traffic congestion. Transportation Research Record: Journal of the Transportation Research Board (2058):163-171.

Baum-Snow N (2007) Did highways cause suburbanization? The Quarterly Journal of Economics 122(2):775-805.

Becker GS (1965) A Theory of the Allocation of Time. The Economic Journal:493-517.

Ben-Akiva M, De Palma A, Isam K (1991) Dynamic network models and driver information systems. Transportation Research Part A: General 25(5):251-266.

Bertrand M, Duflo E, Mullainathan S (2004) How much should we trust differences-in-differences estimates? The Quarterly journal of economics 119(1):249-275.

Bharadwaj S, Bharadwaj A, Bendoly E (2007) The performance effects of complementarities between information systems, marketing, manufacturing, and supply chain processes. Information Systems Research 18(4):437-453.

Blackwell M, Iacus SM, King G, Porro G (2009) CEM: Coarsened exact matching in Stata. The Stata Journal 9(4):524-546.

Bloom N, Garicano L, Sadun R, Reenen JV (2014) The Distinct Effects of Information Technology and Communication Technology on Firm Organization. Management Science.

Bharadwaj AS, Sambamurthy V, Zmud RW (2002) Firmwide IT capability: An empirical examination of the construct and its links to performance. Emory University.

Brynjolfsson E, Hitt LM (2003) Computing Productivity: Firm-Level Evidence. The Review of Economics and Statistics 85(4):793-808.

Cervero R (2002) Induced travel demand: Research design, empirical evidence, and normative policies. Journal of Planning Literature 17(1):3-20.

Chan J, Ghose A (2013) Internet's dirty secret: Assessing the impact of online intermediaries on HIV transmission. MIS Quarterly 38(4):955-976.

Chen Y, Whalley A (2012) Green infrastructure: The effects of urban rail transit on air quality. American Economic Journal: Economic Policy 4(1):58-97.

Cheng ZA, Dimoka A, Pavlou PA (2016) Context may be King, but generalizability is the Emperor! Journal of Information Technology 31(3):257-264.

Couture V, Duranton G, Turner MA (2018) Speed. Review of Economics and Statistics 100(4):725-739.

Dewees DN (1979) Estimating the time costs of highway congestion. Econometrica:1499-1512.

Downs A (1962) The law of peak-hour expressway congestion. Traffic Quarterly 16(3).

Downs A (1992). Stuck in traffic. Washington, DC: The Brookings Institution.

Duranton G, Turner MA (2011) The fundamental law of road congestion: Evidence from US cities. The American Economic Review 101(6):2616-2652. 
El Sawy OA, Malhotra A, Park Y, Pavlou PA (2010) Research Commentary: Seeking the configurations of digital ecodynamics: It takes three to tango. Information Systems Research 21(4):835-848.

Emmerink RH, Verhoef ET, Nijkamp P, Rietveld P (1996) Information provision in road transport with elastic demand: A welfare economic approach. Journal of Transport Economics and Policy:117-136.

Fagnant DJ, Kockelman K (2015) Preparing a nation for autonomous vehicles: opportunities, barriers and policy recommendations. Transportation Research Part A: Policy and Practice 77:167-181.

Ge Y, Knittel CR, MacKenzie D, Zoepf S (2016) Racial and gender discrimination in transportation network companies (National Bureau of Economic Research).

Glaeser E (2011) Triumph of the city: How urban spaces make us human (Pan Macmillan).

Goldfarb A, Tucker C (2019) Digital economics. Journal of Economic Literature 57(1):3-43.

Goodwin PB (1996) Empirical evidence on induced traffic. Transportation 23(1):35-54.

Government Technology (2010). Driving into the Future. 23(6), 14-19.

Government Technology (2011a). Smart highways: Active traffic management technology curbs congestion and improves safety. 24(1), 14-20.

Government Technology (2011b). Taming Traffic: Communities Use Technology to Fight Congestion. 24(7), 16-22.

Granados NF, Gupta A, Kauffman RJ (2006) The Impact of IT on Market Information and Transparency: A Unified Theoretical Framework. Journal of the Association for Information Systems 7(3).

Greenwood BN, Wattal S (2017) Show Me the Way to Go Home: An Empirical Investigation of RideSharing and Alcohol Related Motor Vehicle Fatalities. MIS Quarterly 41(1):163-187.

Hsu WT, Zhang H (2014) The fundamental law of highway congestion revisited: Evidence from national expressways in Japan. Journal of Urban Economics 81:65-76.

Jenkins SP (1995) Easy estimation methods for discrete-time duration models. Oxford Bulletin of Economics and Statistics 57(1):129-136.

Jones P (1998). Urban road pricing: public acceptability and barriers to implementation. Road pricing, traffic congestion and the environment: Issues of efficiency and social feasibility.

Malhotra A, Melville NP, Watson RT (2013) Spurring impactful research on information systems for environmental sustainability. MIS Quarterly 37(4):1265-1274.

Melville NP (2010) Information systems innovation for environmental sustainability. MIS Quarterly 34(1):1-21.

Melville N, Kraemer K, Gurbaxani V (2004) Information technology and organizational performance: An integrative model of IT business value. MIS Quarterly 28(2):283-322.

Michaels G (2008) The effect of trade on the demand for skill: Evidence from the interstate highway system. The Review of Economics and Statistics 90(4):683-701.

Mogridge MJ (1997) The self-defeating nature of urban road capacity policy: A review of theories, disputes and available evidence. Transport Policy 4(1):5-23.

Noland RB (1997) Commuter responses to travel time uncertainty under congested conditions: expected costs and the provision of information. Journal of Urban Economics 41(3):377-406.

Pang MS, Lee G, DeLone WH (2014a) IT resources, organizational capabilities, and value creation in public-sector organizations: a public-value management perspective. Journal of Information Technology 29(3):187-205.

Pang MS, Tafti A, Krishnan MS (2014b). Information Technology and Administrative Efficiency in US State Governments-A Stochastic Frontier Approach. MIS Quarterly 38(4): 1079-1101.

Pang MS, Tafti A, Krishnan MS (2016) Do CIO IT budgets explain bigger or smaller governments? Theory and evidence from US state governments. Management Science 62(4):1020-1041.

Papageorgiou M, Diakaki C, Dinopoulou V, Kotsialos A, Wang Y (2003) Review of road traffic control strategies. Proceedings of the IEEE 91(12):2043-2067.

Pavlou PA, El Sawy OA (2006) From IT leveraging competence to competitive advantage in turbulent environments: The case of new product development. Information Systems Research 17(3):198-227.

Pavlou PA, El Sawy OA (2010) The "third hand": IT-enabled competitive advantage in turbulence through improvisational capabilities. Information Systems Research 21(3):443-471. 
Rai A, Pavlou PA, Im G, Du S (2012) Interfirm IT capability profiles and communications for cocreating relational value: evidence from the logistics industry. MIS Quarterly 36(1):233-262.

Rothenberg J (1970) The economics of congestion and pollution: an integrated view. The American Economic Review:114-121.

Shapiro C, Varian HR (1998) Information rules: a strategic guide to the network economy (Harvard Business Press).

Small KA, Verhoef ET (2007) The economics of urban transportation (Routledge).

Train K (1980) A structured logit model of auto ownership and mode choice. The Review of Economic Studies 47(2):357-370.

Van Dyke CW, Walton JR, Ballinger J (2016). Synthesis of Kentucky's Traveler Information Systems. https://uknowledge.uky.edu/cgi/viewcontent.cgi?article $=2575 \&$ context=ktc researchreports

Vickrey WS (1969) Congestion theory and transport investment. The American Economic Review:251260.

Wachs M (2002) Fighting traffic congestion with information technology. Issues in Science and Technology 19(1):43-50.

Winston C (2013) On the performance of the US transportation system: Caution ahead. Journal of Economic Literature 51(3):773-824.

Winston C, Langer A (2006) The effect of government highway spending on road users' congestion costs. Journal of Urban Economics 60(3):463-483. 


\section{Online Supplementary Appendix A. Details of the Sample}

Table A1. Sample Metropolitan Statistical Areas

\begin{tabular}{|c|c|}
\hline Population Size & Metropolitan Statistical Area (MSA) \\
\hline $\begin{array}{l}\text { Very Large MSA (15) } \\
\geq 3 \text { million population }\end{array}$ & $\begin{array}{l}\text { Atlanta GA; Boston MA-NH-RI; Chicago IL-IN; Dallas-Fort Worth-Arlington } \\
\text { TX; Detroit MI; Houston TX; Los Angeles-Long Beach-Anaheim CA; Miami } \\
\text { FL; New York-Newark NY-NJ-CT; Philadelphia PA-NJ-DE-MD; Phoenix- } \\
\text { Mesa AZ; San Diego CA; San Francisco-Oakland CA; Seattle WA; } \\
\text { Washington DC-VA-MD }\end{array}$ \\
\hline $\begin{array}{l}\text { Large MSA (31) } \\
1 \text { million } \sim 3 \text { million population }\end{array}$ & $\begin{array}{l}\text { Austin TX; Baltimore MD; Charlotte NC-SC; Cincinnati OH-KY-IN; } \\
\text { Cleveland OH; Columbus OH; Denver-Aurora CO; Indianapolis IN; } \\
\text { Jacksonville FL; Kansas City MO-KS; Las Vegas NV; Louisville KY-IN; } \\
\text { Memphis TN-MS-AR; Milwaukee WI; Minneapolis-St. Paul MN; Nashville- } \\
\text { Davidson TN; Oklahoma City OK; Orlando FL; Pittsburgh PA; Portland OR- } \\
\text { WA; Providence RI-MA; Richmond VA; Riverside-San Bernardino CA; } \\
\text { Sacramento CA; Salt Lake City UT; San Antonio TX; San Jose CA; San } \\
\text { Juan PR; St. Louis MO-IL; Tampa-St. Petersburg FL; Virginia Beach VA }\end{array}$ \\
\hline $\begin{array}{l}\text { Medium MSA (33) } \\
500,000 \sim 1 \text { million population }\end{array}$ & $\begin{array}{l}\text { Akron OH; Albany NY; Albuquerque NM; Allentown-Bethlehem PA-NJ; } \\
\text { Bakersfield CA; Baton Rouge LA; Birmingham AL; Bridgeport-Stamford } \\
\text { CT-NY; Buffalo NY; Cape Coral FL; Charleston-North Charleston SC; } \\
\text { Colorado Springs CO; Columbia SC; Dayton OH; El Paso TX-NM; Fresno } \\
\text { CA; Grand Rapids MI; Hartford CT; Honolulu HI; Knoxville TN; McAllen } \\
\text { TX; New Haven CT; New Orleans LA; Omaha NE-IA; Provo-Orem UT; } \\
\text { Raleigh-Durham NC; Rochester NY; Sarasota-Bradenton FL; Springfield } \\
\text { MA-CT; Toledo OH-MI; Tucson AZ; Tulsa OK; Wichita KS }\end{array}$ \\
\hline $\begin{array}{l}\text { Small MSA }(\mathbf{2 2}) \\
\leq 500,000 \text { population }\end{array}$ & $\begin{array}{l}\text { Anchorage AK; Beaumont TX; Boise ID; Boulder CO; Brownsville TX; } \\
\text { Corpus Christi TX; Eugene OR; Greensboro NC; Indio-Cathedral City-Palm } \\
\text { Springs CA; Jackson MS; Lancaster-Palmdale CA; Laredo TX; Little Rock } \\
\text { AR; Madison WI; Oxnard CA; Pensacola FL-AL; Poughkeepsie-Newburgh } \\
\text { NY; Salem OR; Spokane WA-ID; Stockton CA; Winston-Salem NC }\end{array}$ \\
\hline
\end{tabular}




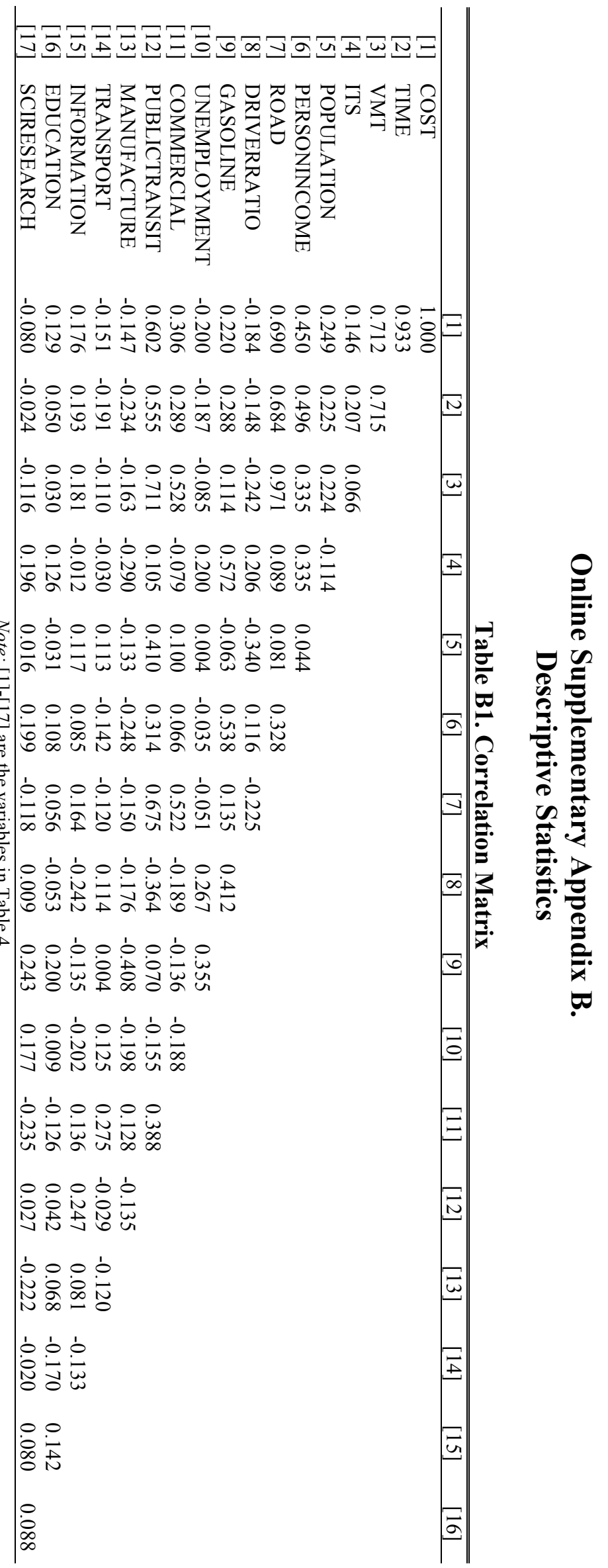




\section{Online Supplementary Appendix C. Robustness and Sensitivity Checks}

Table C1. Comparison of Traffic and Road Congestion Prior to 511 Systems Adoption

\begin{tabular}{|c|c|c|c|c|}
\hline & $\begin{array}{c}\text { Treated MSAs } \\
(\mathrm{N}=68)\end{array}$ & $\begin{array}{c}\text { Untreated MSAs } \\
(\mathrm{N}=31)\end{array}$ & Unconditional & Conditional \\
\hline & (1) & (2) & (3) & (4) \\
\hline \multicolumn{5}{|l|}{ Year $=2000$} \\
\hline COST & $\begin{array}{c}6.818 \\
(0.319)\end{array}$ & $\begin{array}{c}6.612 \\
(0.521)\end{array}$ & $\begin{array}{c}0.206^{* *} \\
(0.085)\end{array}$ & $\begin{array}{c}0.091 \\
(0.065)\end{array}$ \\
\hline TIME & $\begin{array}{c}3.612 \\
(0.281)\end{array}$ & $\begin{array}{c}3.405 \\
(0.479)\end{array}$ & $\begin{array}{c}0.208 * * * \\
(0.077)\end{array}$ & $\begin{array}{c}0.097 \\
(0.059)\end{array}$ \\
\hline TRAFFIC & $\begin{array}{c}9.875 \\
(1.027)\end{array}$ & $\begin{array}{c}9.674 \\
(0.976)\end{array}$ & $\begin{array}{c}0.201 \\
(0.219)\end{array}$ & $\begin{array}{l}-0.022 \\
(0.037)\end{array}$ \\
\hline \multicolumn{5}{|l|}{ Year=1999 } \\
\hline COST & $\begin{array}{c}6.792 \\
(0.333)\end{array}$ & $\begin{array}{c}6.581 \\
(0.546)\end{array}$ & $\begin{array}{l}0.211^{* *} \\
(0.089)\end{array}$ & $\begin{array}{c}0.056 \\
(0.059)\end{array}$ \\
\hline TIME & $\begin{array}{c}3.585 \\
(0.287)\end{array}$ & $\begin{array}{c}3.364 \\
(0.493)\end{array}$ & $\begin{array}{c}0.221 * * * \\
(0.079)\end{array}$ & $\begin{array}{c}0.086 \\
(0.057)\end{array}$ \\
\hline TRAFFIC & $\begin{array}{c}9.860 \\
(1.028)\end{array}$ & $\begin{array}{c}9.635 \\
(0.970)\end{array}$ & $\begin{array}{c}0.224 \\
(0.219)\end{array}$ & $\begin{array}{l}-0.052 \\
(0.042)\end{array}$ \\
\hline \multicolumn{5}{|l|}{ Year $=1998$} \\
\hline COST & $\begin{array}{c}6.744 \\
(0.351)\end{array}$ & $\begin{array}{c}6.537 \\
(0.559)\end{array}$ & $\begin{array}{l}0.206^{* *} \\
(0.092)\end{array}$ & $\begin{array}{c}0.048 \\
(0.059)\end{array}$ \\
\hline TIME & $\begin{array}{c}3.543 \\
(0.299)\end{array}$ & $\begin{array}{c}3.323 \\
(0.504)\end{array}$ & $\begin{array}{c}0.219 * * * \\
(0.081)\end{array}$ & $\begin{array}{c}0.073 \\
(0.045)\end{array}$ \\
\hline TRAFFIC & $\begin{array}{l}9.836 \\
(1.025)\end{array}$ & $\begin{array}{l}9.636 \\
(0.986)\end{array}$ & $\begin{array}{c}0.200 \\
(0.220)\end{array}$ & $\begin{array}{l}-0.030 \\
(0.033)\end{array}$ \\
\hline
\end{tabular}

Note: Table C1 compares the congestion costs, delay hours, and traffic volume (all these are log transformed) between the treated and the untreated MSAs prior to 511 Systems adoption. The comparison is done unconditionally and conditionally (i.e., conditional on the covariates (e.g., population, road stock, gasoline price, employment status in relevant industries) we incorporated in the main specifications. While the treated MSAs on average have higher congestion level than the untreated ones, this difference is not statistically significant after conditional on the observed heterogeneity we have accounted for in our baseline model. 
Table C2. Logit Hazard Models Predicting 511 Systems Adoption

\begin{tabular}{|c|c|c|c|c|c|c|c|}
\hline DV: ITS & $(1)$ & (2) & (3) & (4) & $(5)$ & $(6)$ & $(7)$ \\
\hline POPULATION & $\begin{array}{c}-1.211 * * \\
(0.574)\end{array}$ & $\begin{array}{c}-1.362 * * \\
(0.639)\end{array}$ & $\begin{array}{c}-1.385 * * \\
(0.646)\end{array}$ & $\begin{array}{c}-1.392 * * \\
(0.651)\end{array}$ & $\begin{array}{c}-1.461 * * \\
(0.662)\end{array}$ & $\begin{array}{c}-1.521 * * \\
(0.669)\end{array}$ & $\begin{array}{c}-1.523 * * \\
(0.676)\end{array}$ \\
\hline PERSONINCOME & $\begin{array}{l}-1.016 \\
(1.005)\end{array}$ & $\begin{array}{l}-1.089 \\
(0.989)\end{array}$ & $\begin{array}{l}-1.112 \\
(0.988)\end{array}$ & $\begin{array}{l}-1.127 \\
(0.991)\end{array}$ & $\begin{array}{l}-1.113 \\
(1.005)\end{array}$ & $\begin{array}{l}-1.144 \\
(1.008)\end{array}$ & $\begin{array}{l}-1.150 \\
(1.008)\end{array}$ \\
\hline ROAD & $\begin{array}{l}-0.273 \\
(0.285)\end{array}$ & $\begin{array}{l}-0.457 \\
(0.405)\end{array}$ & $\begin{array}{l}-0.484 \\
(0.408)\end{array}$ & $\begin{array}{l}-0.486 \\
(0.407)\end{array}$ & $\begin{array}{l}-0.485 \\
(0.366)\end{array}$ & $\begin{array}{l}-0.538 \\
(0.374)\end{array}$ & $\begin{array}{l}-0.541 \\
(0.376)\end{array}$ \\
\hline DRIVERRATIO & $\begin{array}{l}-4.977 \\
(3.460)\end{array}$ & $\begin{array}{l}-4.778 \\
(3.374)\end{array}$ & $\begin{array}{l}-4.769 \\
(3.387)\end{array}$ & $\begin{array}{l}-4.802 \\
(3.399)\end{array}$ & $\begin{array}{l}-4.937 \\
(3.421)\end{array}$ & $\begin{array}{l}-4.982 \\
(3.440)\end{array}$ & $\begin{array}{l}-5.063 \\
(3.465)\end{array}$ \\
\hline GASOLINE & $\begin{array}{c}0.656 \\
(1.248)\end{array}$ & $\begin{array}{c}0.514 \\
(1.244)\end{array}$ & $\begin{array}{c}0.512 \\
(1.235)\end{array}$ & $\begin{array}{c}0.530 \\
(1.230)\end{array}$ & $\begin{array}{c}0.495 \\
(1.239)\end{array}$ & $\begin{array}{c}0.463 \\
(1.232)\end{array}$ & $\begin{array}{c}0.474 \\
(1.224)\end{array}$ \\
\hline UNEMPLOYMENT & $\begin{array}{c}-31.979 * * * \\
(10.897)\end{array}$ & $\begin{array}{c}-29.315^{* *} \\
(12.400)\end{array}$ & $\begin{array}{c}-29.300 * * \\
(12.125)\end{array}$ & $\begin{array}{c}-29.553 * * \\
(11.949)\end{array}$ & $\begin{array}{c}-26.966^{* * *} \\
(13.318)\end{array}$ & $\begin{array}{c}-26.131 * * \\
(13.195)\end{array}$ & $\begin{array}{c}-26.334 * * \\
(13.131)\end{array}$ \\
\hline COMMERCIAL & $\begin{array}{l}-0.018 \\
(0.216)\end{array}$ & $\begin{array}{l}-0.001 \\
(0.212)\end{array}$ & $\begin{array}{c}0.002 \\
(0.213)\end{array}$ & $\begin{array}{c}0.003 \\
(0.213)\end{array}$ & $\begin{array}{l}-0.001 \\
(0.201)\end{array}$ & $\begin{array}{c}0.001 \\
(0.198)\end{array}$ & $\begin{array}{c}0.001 \\
(0.199)\end{array}$ \\
\hline PUBLICTRANSIT & $\begin{array}{l}0.255^{*} \\
(0.153)\end{array}$ & $\begin{array}{l}0.260^{*} \\
(0.158)\end{array}$ & $\begin{array}{c}0.260 \\
(0.158)\end{array}$ & $\begin{array}{c}0.259 \\
(0.158)\end{array}$ & $\begin{array}{l}0.276^{*} \\
(0.160)\end{array}$ & $\begin{array}{l}0.284^{*} \\
(0.161)\end{array}$ & $\begin{array}{l}0.285^{*} \\
(0.161)\end{array}$ \\
\hline MANUFACTURE & $\begin{array}{l}-2.237 \\
(3.566)\end{array}$ & $\begin{array}{l}-2.639 \\
(3.651)\end{array}$ & $\begin{array}{l}-2.755 \\
(3.680)\end{array}$ & $\begin{array}{l}-2.827 \\
(3.703)\end{array}$ & $\begin{array}{l}-2.330 \\
(3.507)\end{array}$ & $\begin{array}{l}-2.349 \\
(3.509)\end{array}$ & $\begin{array}{l}-2.380 \\
(3.521)\end{array}$ \\
\hline TRANSPORT & $\begin{array}{c}1.236 \\
(5.536)\end{array}$ & $\begin{array}{c}1.873 \\
(5.957)\end{array}$ & $\begin{array}{c}1.987 \\
(6.065)\end{array}$ & $\begin{array}{c}2.026 \\
(6.105)\end{array}$ & $\begin{array}{c}2.958 \\
(6.393)\end{array}$ & $\begin{array}{c}3.375 \\
(6.550)\end{array}$ & $\begin{array}{c}3.345 \\
(6.575)\end{array}$ \\
\hline INFORMATION & $\begin{array}{c}-1.935 \\
(11.455)\end{array}$ & $\begin{array}{c}-1.461 \\
(11.413)\end{array}$ & $\begin{array}{c}-1.216 \\
(11.465)\end{array}$ & $\begin{array}{c}-1.012 \\
(11.524)\end{array}$ & $\begin{array}{c}-2.775 \\
(11.159)\end{array}$ & $\begin{array}{c}-2.940 \\
(11.128)\end{array}$ & $\begin{array}{c}-2.842 \\
(11.169)\end{array}$ \\
\hline EDUCATION & $\begin{array}{c}5.637 \\
(8.295)\end{array}$ & $\begin{array}{c}4.836 \\
(9.047)\end{array}$ & $\begin{array}{c}4.607 \\
(9.245)\end{array}$ & $\begin{array}{c}4.416 \\
(9.263)\end{array}$ & $\begin{array}{c}5.715 \\
(9.020)\end{array}$ & $\begin{array}{c}5.725 \\
(9.234)\end{array}$ & $\begin{array}{c}5.621 \\
(9.205)\end{array}$ \\
\hline SCIRESEARCH & $\begin{array}{c}5.065 \\
(5.487)\end{array}$ & $\begin{array}{c}4.471 \\
(5.503)\end{array}$ & $\begin{array}{c}4.412 \\
(5.470)\end{array}$ & $\begin{array}{c}4.476 \\
(5.427)\end{array}$ & $\begin{array}{c}3.984 \\
(5.502)\end{array}$ & $\begin{array}{c}3.709 \\
(5.472)\end{array}$ & $\begin{array}{c}3.695 \\
(5.460)\end{array}$ \\
\hline $\operatorname{cosT}_{t-1}$ & & $\begin{array}{c}0.749 \\
(1.036)\end{array}$ & & & & & \\
\hline $\operatorname{cosT}_{t-2}$ & & & $\begin{array}{c}0.829 \\
(1.033)\end{array}$ & & & & \\
\hline $\operatorname{COST}_{\mathrm{t}-3}$ & & & & $\begin{array}{c}0.813 \\
(1.003)\end{array}$ & & & \\
\hline TIME $_{\mathrm{t}-1}$ & & & & & $\begin{array}{c}0.960 \\
(0.984)\end{array}$ & & \\
\hline TIME $_{\mathrm{t}-2}$ & & & & & & $\begin{array}{c}1.163 \\
(1.023)\end{array}$ & \\
\hline TIME $_{t-3}$ & & & & & & & $\begin{array}{c}1.134 \\
(1.018)\end{array}$ \\
\hline Year FE & YES & YES & YES & YES & YES & YES & YES \\
\hline \# of Observations & 794 & 695 & 695 & 695 & 695 & 695 & 695 \\
\hline
\end{tabular}


Table C3: 2SLS Estimation of the Effects of 511 Systems Adoption on Traffic Congestion ${ }^{*}$

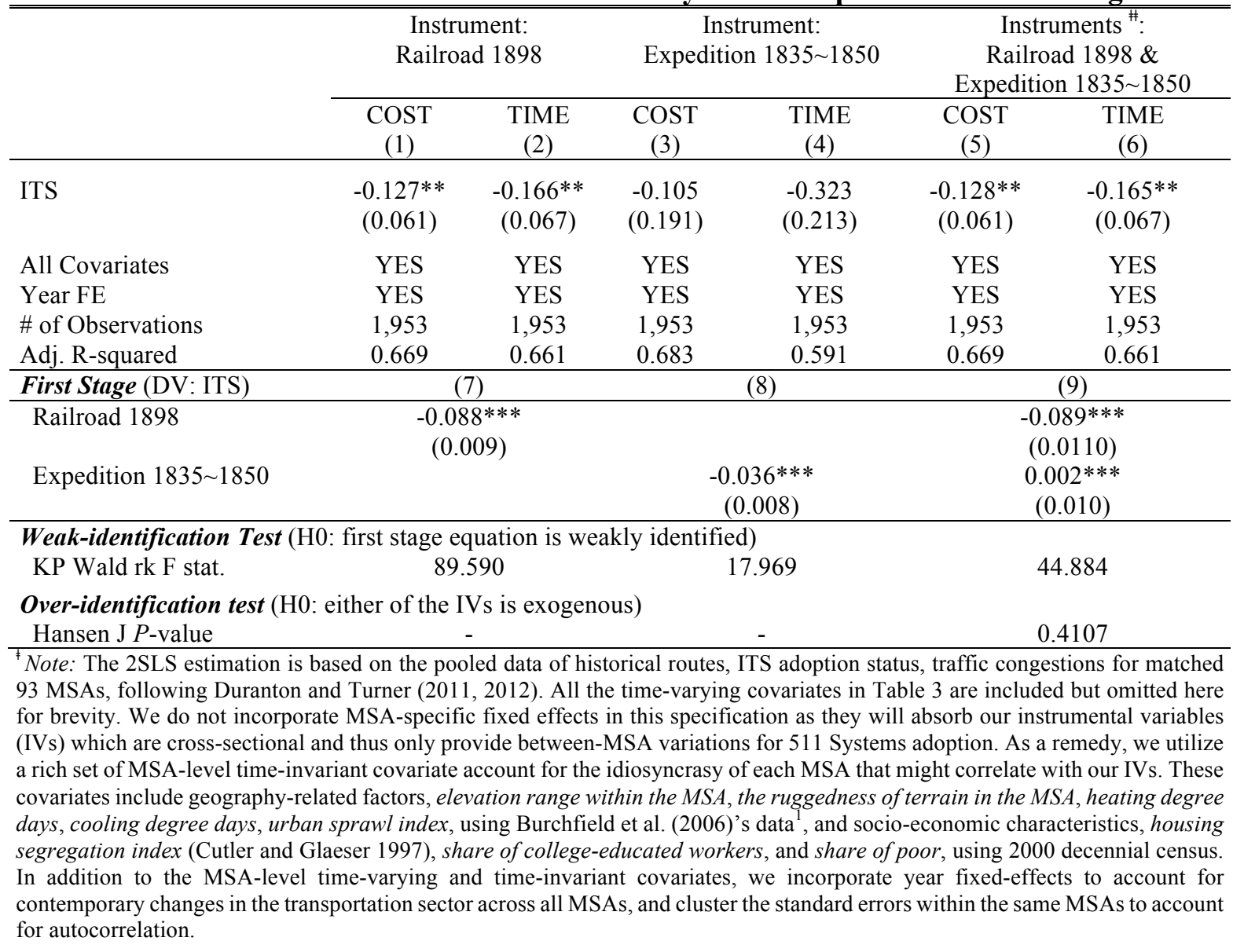

\# Note: The two IVs are 1898 railroad route kilometers and the incidence of major expeditions of exploration between 1835 and 1850. We test two assumptions, relevance and exogeneity, for validity as an IV. To check the relevance, we use Kleibergen-Paap Wald F statistic and Stock-Yogo weak TD test for the first stage regression of IVs on 511 Systems adoption (Stock and Yogo 2002). The results significantly reject the null hypotheses that the IVs are weak. To investigate the exogeneity, we used Hansen J test. The results do not reject the null hypotheses that either of the IVs is exogenous. Heteroskedasticity-adjusted standard errors, clustered at the MSA level, are included in parentheses. ${ }^{* * *} \mathrm{p}<0.01, * * \mathrm{p}<0.05,{ }^{*} \mathrm{p}<0.1$

Figure C1. 1898 Railroads

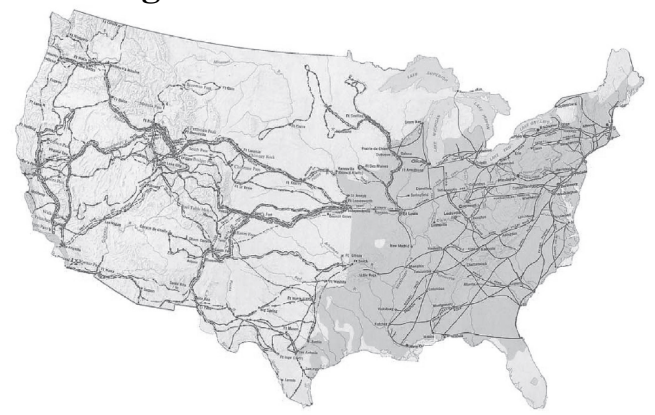

Figure C2. Routes of US Major Expeditions of Exploration, 1835 to 1850

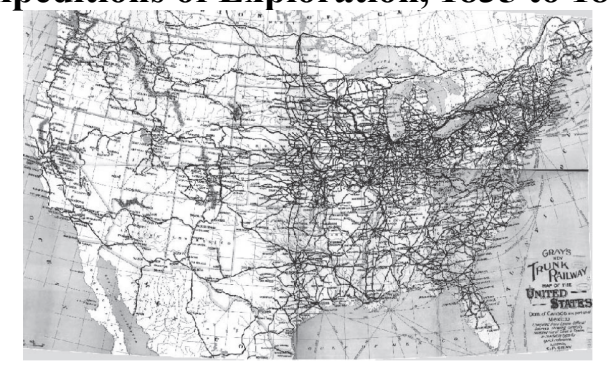

(Source: Duranton and Turner 2011)

\footnotetext{
${ }^{1}$ http://diegopuga.org/data/sprawl/, retrieved on February 20, 2018.
} 
Table C4. Replicating Table 5 Using Various Subsamples

\begin{tabular}{|c|c|c|c|c|c|c|c|c|}
\hline & \multicolumn{2}{|c|}{$\begin{array}{l}\text { Only MSAs that do } \\
\text { not span } \\
\text { across states }\end{array}$} & \multicolumn{2}{|c|}{$\begin{array}{c}\text { Only MSAs that } \\
\text { adopted } 511 \text { Systems } \\
\text { by state government } \\
\text { decisions }\end{array}$} & \multicolumn{2}{|c|}{$\begin{array}{c}\text { Only MSAs that } \\
\text { adopted } 511 \text { Systems } \\
\text { by city government } \\
\text { decisions) }\end{array}$} & \multicolumn{2}{|c|}{$\begin{array}{c}\text { Only Observations } \\
\text { until } 2008 \\
\text { (before the } 2009 \\
\text { Financial Crisis) }\end{array}$} \\
\hline & $\begin{array}{c}\text { COST } \\
(1) \\
\end{array}$ & $\begin{array}{l}\text { TIME } \\
(2) \\
\end{array}$ & $\begin{array}{c}\text { COST } \\
(3) \\
\end{array}$ & $\begin{array}{c}\text { TIME } \\
(4)\end{array}$ & $\begin{array}{c}\text { COST } \\
(5) \\
\end{array}$ & $\begin{array}{l}\text { TIME } \\
(6)\end{array}$ & $\begin{array}{c}\text { COST } \\
(7) \\
\end{array}$ & $\begin{array}{c}\text { TIME } \\
(8)\end{array}$ \\
\hline ITS & $\begin{array}{c}-0.027 * * * \\
(0.008)\end{array}$ & $\begin{array}{c}-0.025 * * * \\
(0.008)\end{array}$ & $\begin{array}{l}-0.012 * \\
(0.007)\end{array}$ & $\begin{array}{l}-0.010 \\
(0.007)\end{array}$ & $\begin{array}{c}-0.147 * * * \\
(0.034)\end{array}$ & $\begin{array}{c}-0.141 * * * \\
(0.031)\end{array}$ & $\begin{array}{l}-0.017 * \\
(0.010)\end{array}$ & $\begin{array}{l}-0.015^{*} \\
(0.009)\end{array}$ \\
\hline POPULATION & $\begin{array}{c}0.960 * * * \\
(0.039)\end{array}$ & $\begin{array}{c}0.024 \\
(0.038)\end{array}$ & $\begin{array}{c}0.991 * * * \\
(0.036)\end{array}$ & $\begin{array}{l}0.069^{*} \\
(0.037)\end{array}$ & $\begin{array}{c}1.571 * * * \\
(0.185)\end{array}$ & $\begin{array}{c}0.774 * * * \\
(0.172)\end{array}$ & $\begin{array}{c}1.175 * * * \\
(0.056)\end{array}$ & $\begin{array}{c}0.167 * * * \\
(0.053)\end{array}$ \\
\hline PERSONINCOME & $\begin{array}{c}0.207 * * * \\
(0.045)\end{array}$ & $\begin{array}{c}0.491 * * * \\
(0.045)\end{array}$ & $\begin{array}{c}0.005 \\
(0.010)\end{array}$ & $\begin{array}{c}0.022 \\
(0.024)\end{array}$ & $\begin{array}{c}0.085 \\
(0.178)\end{array}$ & $\begin{array}{l}0.335 * \\
(0.171)\end{array}$ & $\begin{array}{c}0.084 \\
(0.067)\end{array}$ & $\begin{array}{c}0.067 \\
(0.064)\end{array}$ \\
\hline ROAD & $\begin{array}{c}0.965 * * * \\
(0.038)\end{array}$ & $\begin{array}{c}0.040 \\
(0.037)\end{array}$ & $\begin{array}{c}1.018 * * * \\
(0.035)\end{array}$ & $\begin{array}{c}0.111 * * * \\
(0.036)\end{array}$ & $\begin{array}{c}1.718 * * * \\
(0.184)\end{array}$ & $\begin{array}{c}0.878 * * * \\
(0.172)\end{array}$ & $\begin{array}{c}1.179 * * * \\
(0.056)\end{array}$ & $\begin{array}{c}0.175 * * * \\
(0.053)\end{array}$ \\
\hline DRIVERRATIO & $\begin{array}{c}1.977 * * * \\
(0.272)\end{array}$ & $\begin{array}{c}1.354 * * * \\
(0.276)\end{array}$ & $\begin{array}{c}2.241 * * * \\
(0.222)\end{array}$ & $\begin{array}{c}2.647 * * * \\
(0.261)\end{array}$ & $\begin{array}{c}3.315^{* * * *} \\
(0.947)\end{array}$ & $\begin{array}{c}2.582 * * * \\
(0.880)\end{array}$ & $\begin{array}{c}1.962 * * * \\
(0.324)\end{array}$ & $\begin{array}{l}0.538^{*} \\
(0.324)\end{array}$ \\
\hline GASOLINE & $\begin{array}{c}-0.059 * * * \\
(0.010)\end{array}$ & $\begin{array}{l}-0.007 \\
(0.010)\end{array}$ & $\begin{array}{c}-0.034 * * * \\
(0.007)\end{array}$ & $\begin{array}{c}0.056^{* * *} \\
(0.008)\end{array}$ & $\begin{array}{c}0.003 \\
(0.035)\end{array}$ & $\begin{array}{c}0.033 \\
(0.033)\end{array}$ & $\begin{array}{c}0.042 \\
(0.034)\end{array}$ & $\begin{array}{c}0.031 \\
(0.033)\end{array}$ \\
\hline UNEMPLOYMENT & $\begin{array}{c}-0.737 * * * \\
(0.245)\end{array}$ & $\begin{array}{l}-0.316 \\
(0.229)\end{array}$ & $\begin{array}{c}-0.913 * * * \\
(0.208)\end{array}$ & $\begin{array}{c}-0.910 * * * \\
(0.206)\end{array}$ & $\begin{array}{c}0.327 \\
(0.673)\end{array}$ & $\begin{array}{c}0.152 \\
(0.642)\end{array}$ & $\begin{array}{c}-0.949 * * * \\
(0.336)\end{array}$ & $\begin{array}{c}-0.854 * * * \\
(0.316)\end{array}$ \\
\hline COMMERCIAL & $\begin{array}{c}0.018 * * * \\
(0.004)\end{array}$ & $\begin{array}{c}0.019 * * * \\
(0.004)\end{array}$ & $\begin{array}{l}0.009^{*} \\
(0.005)\end{array}$ & $\begin{array}{c}0.003 \\
(0.005)\end{array}$ & $\begin{array}{c}0.026 \\
(0.025)\end{array}$ & $\begin{array}{c}0.008 \\
(0.024)\end{array}$ & $\begin{array}{c}0.011 * * * \\
(0.003)\end{array}$ & $\begin{array}{c}0.010 * * * \\
(0.003)\end{array}$ \\
\hline PUBLICTRANSIT & $\begin{array}{c}0.030 * * * \\
(0.006)\end{array}$ & $\begin{array}{c}0.030 * * * \\
(0.006)\end{array}$ & $\begin{array}{c}0.026 * * * \\
(0.005)\end{array}$ & $\begin{array}{c}0.022 * * * \\
(0.005)\end{array}$ & $\begin{array}{c}0.015 \\
(0.046)\end{array}$ & $\begin{array}{c}0.037 \\
(0.041)\end{array}$ & $\begin{array}{c}0.025 * * * \\
(0.006)\end{array}$ & $\begin{array}{c}0.022 * * * \\
(0.006)\end{array}$ \\
\hline MANUFACTURE & $\begin{array}{l}-0.170 \\
(0.131)\end{array}$ & $\begin{array}{c}-0.340 * * * \\
(0.123)\end{array}$ & $\begin{array}{c}0.002 \\
(0.092)\end{array}$ & $\begin{array}{l}-0.126 \\
(0.092)\end{array}$ & $\begin{array}{c}0.448 \\
(0.612)\end{array}$ & $\begin{array}{c}0.475 \\
(0.601)\end{array}$ & $\begin{array}{l}-0.095 \\
(0.090)\end{array}$ & $\begin{array}{l}-0.090 \\
(0.087)\end{array}$ \\
\hline TRANSPORT & $\begin{array}{c}-0.902 * \\
(0.468)\end{array}$ & $\begin{array}{c}-0.308 \\
(0.444)\end{array}$ & $\begin{array}{c}-0.787 * * \\
(0.368)\end{array}$ & $\begin{array}{l}-0.438 \\
(0.368)\end{array}$ & $\begin{array}{c}-6.274 * * * \\
(2.103)\end{array}$ & $\begin{array}{c}-3.389 * \\
(2.011)\end{array}$ & $\begin{array}{c}0.437 \\
(0.372)\end{array}$ & $\begin{array}{c}0.470 \\
(0.355)\end{array}$ \\
\hline INFORMATION & $\begin{array}{c}1.195 * * * \\
(0.393)\end{array}$ & $\begin{array}{c}1.153 * * * \\
(0.379)\end{array}$ & $\begin{array}{c}0.190 \\
(0.290)\end{array}$ & $\begin{array}{l}-0.020 \\
(0.297)\end{array}$ & $\begin{array}{c}8.446 * * * \\
(2.111)\end{array}$ & $\begin{array}{c}8.193 * * * \\
(2.032)\end{array}$ & $\begin{array}{c}0.219 \\
(0.262)\end{array}$ & $\begin{array}{c}0.194 \\
(0.255)\end{array}$ \\
\hline EDUCATION & $\begin{array}{c}-0.393 \\
(0.295)\end{array}$ & $\begin{array}{l}-0.098 \\
(0.312)\end{array}$ & $\begin{array}{l}-0.325 \\
(0.227)\end{array}$ & $\begin{array}{c}0.122 \\
(0.236)\end{array}$ & $\begin{array}{c}-9.180 * * * \\
(2.416)\end{array}$ & $\begin{array}{c}-6.983 * * * \\
(2.161)\end{array}$ & $\begin{array}{c}-0.538^{*} \\
(0.309)\end{array}$ & $\begin{array}{l}-0.436 \\
(0.303)\end{array}$ \\
\hline SCIRESEARCH & $\begin{array}{c}-1.021 * * * \\
(0.107)\end{array}$ & $\begin{array}{c}-0.985 * * * \\
(0.098)\end{array}$ & $\begin{array}{c}-0.859 * * * \\
(0.098)\end{array}$ & $\begin{array}{c}-0.727 * * * \\
(0.093)\end{array}$ & $\begin{array}{c}-0.778 * * \\
(0.387)\end{array}$ & $\begin{array}{l}-0.614 \\
(0.393)\end{array}$ & $\begin{array}{c}-0.782 * * * \\
(0.094)\end{array}$ & $\begin{array}{c}-0.739 * * * \\
(0.083)\end{array}$ \\
\hline $\begin{array}{l}\text { MSA FE } \\
\text { Year FE }\end{array}$ & $\begin{array}{l}\text { YES } \\
\text { YES }\end{array}$ & $\begin{array}{l}\text { YES } \\
\text { YES }\end{array}$ & $\begin{array}{l}\text { YES } \\
\text { YES }\end{array}$ & $\begin{array}{l}\text { YES } \\
\text { YES }\end{array}$ & $\begin{array}{l}\text { YES } \\
\text { YES }\end{array}$ & $\begin{array}{l}\text { YES } \\
\text { YES }\end{array}$ & $\begin{array}{l}\text { YES } \\
\text { YES }\end{array}$ & $\begin{array}{l}\text { YES } \\
\text { YES }\end{array}$ \\
\hline $\begin{array}{l}\text { \# of Observations } \\
\text { \# of MSAs }\end{array}$ & $\begin{array}{c}1,596 \\
76\end{array}$ & $\begin{array}{c}1,596 \\
76\end{array}$ & $\begin{array}{c}1,827 \\
87\end{array}$ & $\begin{array}{c}1,827 \\
87\end{array}$ & $\begin{array}{c}210 \\
10\end{array}$ & $\begin{array}{c}210 \\
10\end{array}$ & $\begin{array}{c}1,485 \\
99\end{array}$ & $\begin{array}{c}1,485 \\
99\end{array}$ \\
\hline Adjusted R-squared & 0.952 & 0.952 & 0.949 & 0.937 & 0.982 & 0.984 & 0.967 & 0.964 \\
\hline
\end{tabular}




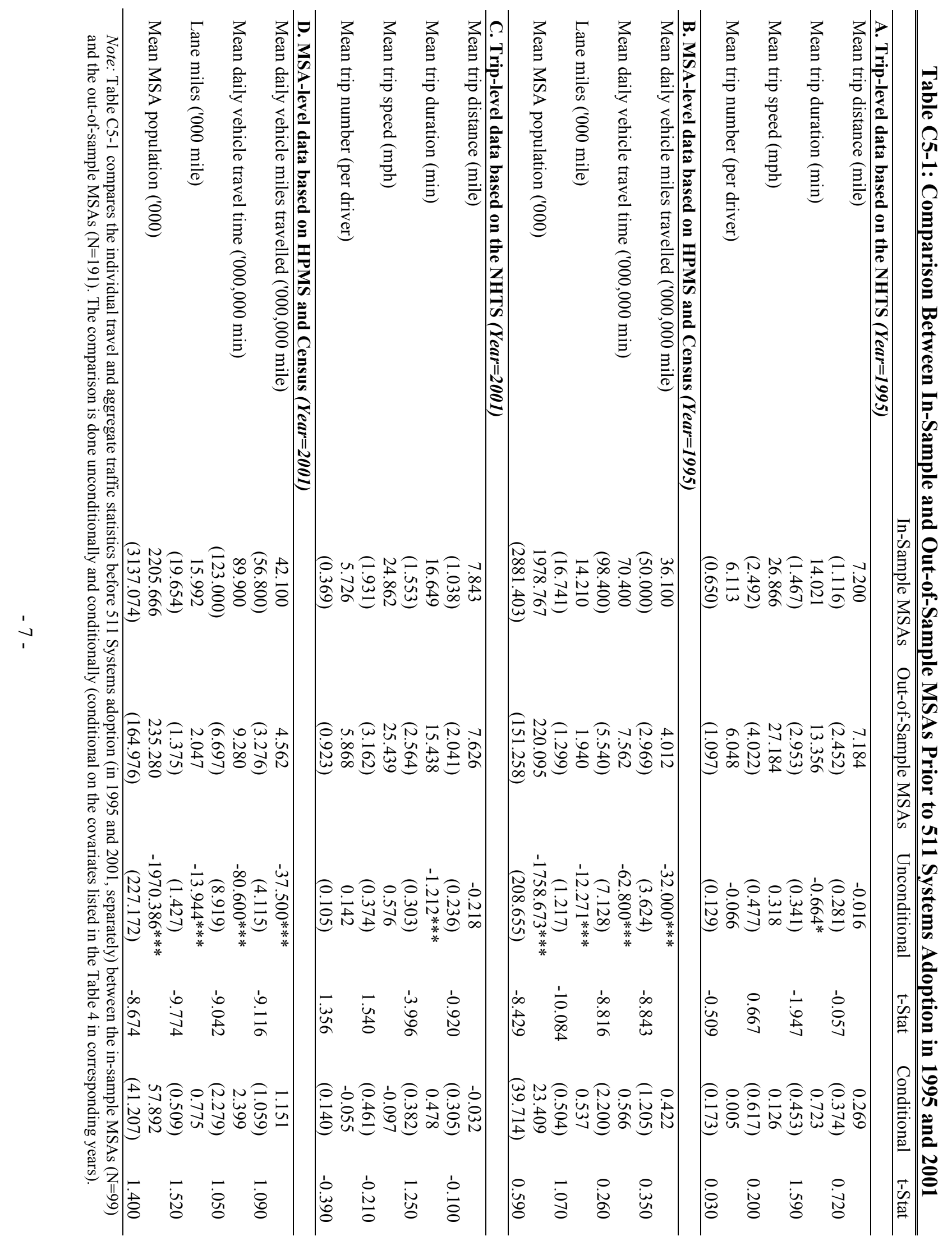




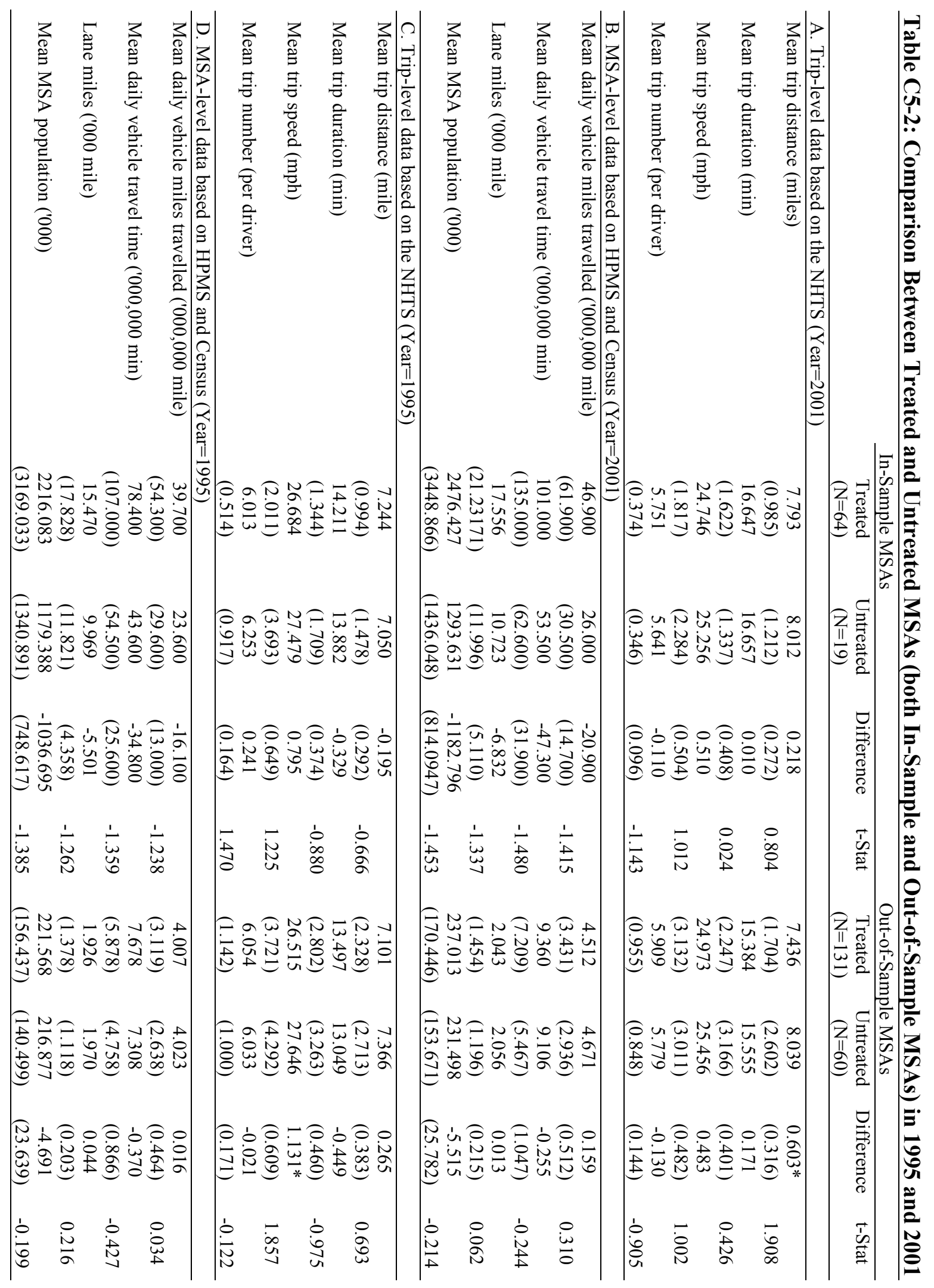


Table C6. Difference-in-Differences Regressions Adjusted by Coarsened Exact Matching

\begin{tabular}{lcc}
\hline \hline & COST & TIME \\
\cline { 2 - 3 } ITS & $(1)$ & $(2)$ \\
& $-0.023 * * *$ & $-0.020^{* *}$ \\
& $(0.009)$ & $(0.008)$ \\
All Covariates & YES & YES \\
MSA FE & YES & YES \\
Year FE & YES & YES \\
\# of Observations & 1,706 & 1,706 \\
\# of MSAs & 85 & 85 \\
Adj. R-squared & 0.946 & 0.942 \\
\hline
\end{tabular}

Note: Table C6 reports the results from difference-in-differences regressions using weights generated by coarsened exact matching. The matching is based on the population size, unemployment rate, road miles, and traffic volume one year before 511 Systems adoption. These variables are chosen because they are unbalanced for treated and untreated cities. Heteroscedasticityadjusted standard errors, clustered at the MSA level, are included in parentheses. $* * * \mathrm{p}<0.01, * * \mathrm{p}<0.05, * \mathrm{p}<0.1$

Table C7. Random (Shuffled) Implementation Test

\begin{tabular}{lcc}
\hline \hline \multirow{2}{*}{ Estimation } & COST & TIME \\
\cline { 2 - 3 } & $(1)$ & $(2)$ \\
\hline$\mu$ of Random $\beta$ & -0.00002 & 0.00006 \\
of Random $\beta$ & 0.00370 & 0.00354 \\
Eeplications & 1000 & 1000 \\
Zstimated $\beta$ & -0.029 & -0.26 \\
P-Value & -7.84384 & -7.3312 \\
\hline
\end{tabular}

Note: Table $\mathrm{C} 7$ reports the results from difference-in-differences regressions using randomly generated placebo variables as independent variables. The placebo generation and regression are replicated 1000 times. $\mu$ is the mean of the placebo estimator, while $\sigma$ is its standard error. This diagnostic test is to determine the probability of the observed effect occurring purely by chance. The comparison between a placebo effect and an estimated effect are statistically significantly different $(p<0.01)$, thus eliminating the aforementioned possibility.

\section{Figure C3. Distribution of Coefficients based on Random Treatments}
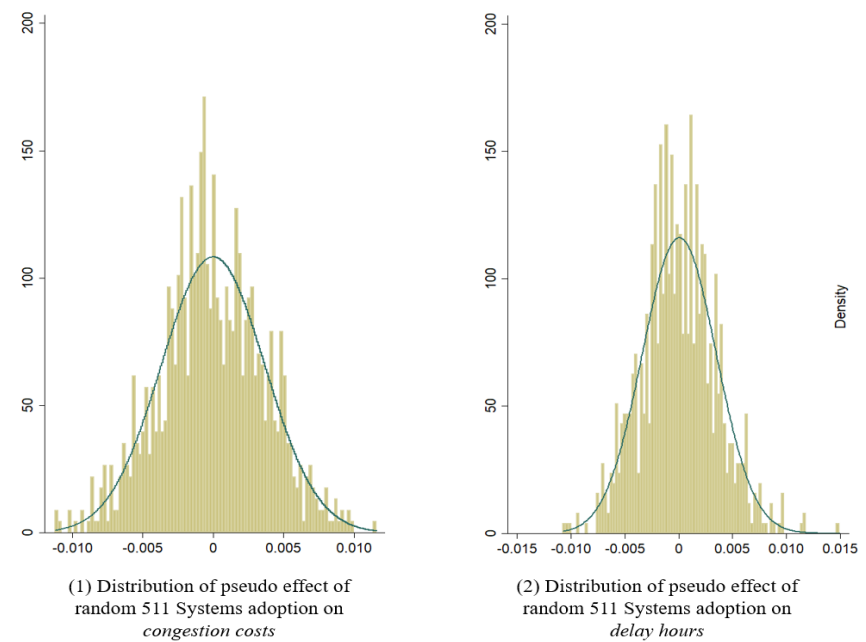

Note: Figure C3 describes the distributions of the DID estimates of placebo 511 Systems adoption generated from 1,000 replications. As expected, the distributions of the pseudo effects are centered around zero. Together with Table $\mathrm{C} 7$, the findings from the random (shuffled) treatment test suggest the observed effect of 511 Systems on congestion costs $(-0.029, p<0.01)$, and on delay hours ($0.026, p<0.01)$ are unlikely obtained by random chance. 
Table C8. Replicating Table 5 with Aggregate Congestion Measure

\begin{tabular}{lcccc}
\hline \hline DVs are total congestion cost, time, fuel & COST & TIME & FUEL & CO2 \\
\cline { 2 - 5 } and CO2 aggregated to the city level & $(1)$ & $(2)$ & $(3)$ & $(4)$ \\
\hline ITS & $-0.028^{* * *}$ & $-0.028^{* * *}$ & $-0.028^{* * *}$ & $-0.043^{* * *}$ \\
& $(0.007)$ & $(0.007)$ & $(0.007)$ & $(0.015)$ \\
All Covariates & YES & YES & YES & YES \\
MSA FE & YES & YES & YES & YES \\
Year FE & YES & YES & YES & YES \\
\# of Observations & 2,079 & 2,079 & 2,079 & 1,089 \\
\# of MSAs & 99 & 99 & 99 & 99 \\
Adjusted R-squared & 0.995 & 0.995 & 0.995 & 0.990 \\
\hline
\end{tabular}

Note: Table $\mathrm{C} 8$ reports a replication of the main analyses by using aggregate congestion (instead of average congestion per commuter) measures on COST, TIME, FUEL, CO2 (only available for 2001-2014) as dependent variables. Heteroscedasticityadjusted standard errors, clustered at the MSA level, are included in parentheses. ${ }^{* * *} \mathrm{p}<0.01,{ }^{* *} \mathrm{p}<0.05,{ }^{*} \mathrm{p}<0.1$

Table C9. Replicating Table 5 with Alternative ITS Measures

\begin{tabular}{|c|c|c|c|c|}
\hline & \multicolumn{2}{|c|}{$\begin{array}{l}\text { ITS variables for MSAs adopted } 511 \\
\text { Systems in the } 4 \text { th quarter of a year are } \\
\text { labeled as adopted in the following year. }\end{array}$} & \multicolumn{2}{|c|}{$\begin{array}{l}\text { ITS variables for MSAs } \\
\text { that span across states are weighted by the } \\
\text { share of areas size in each state. }\end{array}$} \\
\hline & COST & TIME & COST & TIME \\
\hline & (1) & (2) & (3) & (4) \\
\hline ITS & $\begin{array}{c}-0.030 * * * \\
(0.007)\end{array}$ & $\begin{array}{c}-0.027 * * * \\
(0.006)\end{array}$ & $\begin{array}{c}-0.020 * * * \\
(0.007)\end{array}$ & $\begin{array}{c}-0.018 * * * \\
(0.006)\end{array}$ \\
\hline All Covariates & YES & YES & YES & YES \\
\hline MSA FE & YES & YES & YES & YES \\
\hline Year FE & YES & YES & YES & YES \\
\hline \# of Observations & 2,079 & 2,079 & 2,079 & 2,079 \\
\hline \# of MSAs & 99 & 99 & 99 & 99 \\
\hline Adjusted R-squared & 0.956 & 0.954 & 0.956 & 0.954 \\
\hline
\end{tabular}

Note: Table C9 reports a replication of the baseline analysis with alternative ITS measures as independent variables. Heteroscedasticity-adjusted standard errors clustered at the MSA level, are included in parentheses. ${ }^{* * *} \mathrm{p}<0.01,{ }^{* *} \mathrm{p}<0.05,{ }^{*} \mathrm{p}<0.1$

Table C10. Effects of Search Popularity of "Google Maps" on Traffic Congestion

\begin{tabular}{|c|c|c|c|c|}
\hline & COST & COST & TIME & TIME \\
\hline & (1) & (2) & (3) & (4) \\
\hline GOOGLEMAPS & $\begin{array}{l}-0.00027 \\
(0.00018)\end{array}$ & $\begin{array}{c}0.00008 \\
(0.00023)\end{array}$ & $\begin{array}{l}-0.00033^{*} \\
(0.00018)\end{array}$ & $\begin{array}{c}0.00000 \\
(0.00022)\end{array}$ \\
\hline ITS & $\begin{array}{c}-0.02756 * * * \\
(0.00699)\end{array}$ & $\begin{array}{c}-0.02393 * * * \\
(0.00863)\end{array}$ & $\begin{array}{c}-0.02518 * * * \\
(0.00671)\end{array}$ & $\begin{array}{c}-0.02070 * * \\
(0.00832)\end{array}$ \\
\hline GOOGLEMAPS $\times$ ITS & & $\begin{array}{c}-0.00052 * * * \\
(0.00018)\end{array}$ & & $\begin{array}{c}-0.00049 * * * \\
(0.00017)\end{array}$ \\
\hline All Covariates & YES & YES & YES & YES \\
\hline MSA FE & YES & YES & YES & YES \\
\hline Year FE & YES & YES & YES & YES \\
\hline \# of Observations & 2,079 & 2,079 & 2,079 & 2,079 \\
\hline \# of MSAs & 99 & 99 & 99 & 99 \\
\hline Adj. R-squared & 0.955 & 0.956 & 0.954 & 0.954 \\
\hline
\end{tabular}




\section{Online Supplementary Appendix D. Underlying Mechanisms}

Table D1. Effects of 511 Systems Adoption on Travel Time to Work for Drivers

\begin{tabular}{lcccc}
\hline \hline $\begin{array}{l}\text { DV: } \\
\begin{array}{l}\text { In (Travel Time to Work } \\
\text { (minutes)) }\end{array}\end{array}$ & All drivers & $\begin{array}{c}\text { Drivers } \\
\text { who commute } \\
\text { to work within } \\
60 \text { mins }\end{array}$ & $\begin{array}{c}\text { Drivers } \\
\text { who commute to work } \\
\text { within } 60 \text { mins in } \\
\text { heavy-traffic hours }\end{array}$ & $\begin{array}{c}\text { Drivers } \\
\text { who commute to } \\
\text { work within } 60 \text { mins } \\
\text { in light-traffic hours }\end{array}$ \\
\cline { 2 - 5 } & $(1)$ & $(2)$ & $(3)$ & $(4)$ \\
ITS & 0.0002 & $-0.0312^{*}$ & $-0.0467 * *$ & 0.0002 \\
Covariates, State \& Year FE & $(0.0261)$ & $(0.0190)$ & $(0.0231)$ & $(0.0329)$ \\
\# of Observations & YES & YES & YES & YES \\
Adj. R-squared & $8,736,734$ & $8,519,288$ & $5,472,806$ & $3,046,482$ \\
\hline
\end{tabular}

Note: Table D1 reports the results from DID estimations of 511 Systems adoption on travel time to work at the individual commuteryear level. The data are from American Community Survey 1-year estimate on participants in 41 states matched to our sampled states in 2000-2014. California, Texas, and Ohio are dropped because MSAs in these states adopted 511 Systems at different years. In Column 1, we restrict the survey responders to those who commute by driving. In Column 2, we restrict the data to drivers whose commuting time is less than 60 minutes. In Column 3 and 4, we restrict to drivers whose travel time is within 60 minutes and who do or do not travel during peak hours. The covariates are included but omitted for brevity: they are individual-level controls (i.e., age, gender, race, employment status, personal incomes, car ownership) and state-level controls (i.e., population, road miles, employment share in the manufacture, transportation, and information-related sectors). Heteroscedasticity-adjusted standard errors, clustered at the state level, are included in parentheses. ${ }^{* * *} \mathrm{p}<0.01, * * \mathrm{p}<0.05, * \mathrm{p}<0.1$

Table D2. Effects of 511 Systems Adoption on Departure Time Choice for Drivers

\begin{tabular}{lcc}
\hline \hline DV: & All drivers & $\begin{array}{c}\text { Drivers who commute to work } \\
\text { within 60 min }\end{array}$ \\
(=1 if Yes, =0 if at light-traffic hours) & $(1)$ & $(2)$ \\
\hline & $-0.0013^{* *}$ & $-0.0016^{* *}$ \\
ITS & $(0.0007)$ & $(0.0007)$ \\
Covariates, State \& Year FE & YES & YES \\
\# of Observations & $8,289,590$ & $8,084,254$ \\
Adj. R-squared & 0.0179 & 0.0180 \\
\hline
\end{tabular}

Note: Table D2 reports the results from DID estimations of 511 Systems adoption on departure time to work. All covariates in Table D1 are included here but are omitted for brevity. Heteroscedasticity-adjusted standard errors, clustered at the state level, are included in parentheses. ${ }^{* * *} \mathrm{p}<0.01, * * \mathrm{p}<0.05, * \mathrm{p}<0.1$

Table D3. Effects of 511 Systems Adoption on Transportation Mode to Work

\begin{tabular}{lcccccc}
\hline \hline & \multicolumn{3}{c}{ Private Transit } & \multicolumn{3}{c}{ Public Transit } \\
\cline { 2 - 7 } & Private Car & Taxi & Walk \& Bike & Bus & Rail & Total \\
\cline { 2 - 7 } & $(1)$ & $(2)$ & $(3)$ & $(4)$ & $(5)$ & $(6)$ \\
\hline \multirow{3}{*}{ ITS } & $-0.0025^{* * *}$ & $-0.0002^{* * *}$ & $0.0005^{* *}$ & $-0.0009^{* * *}$ & $0.0031^{* * *}$ & $0.0021^{* * *}$ \\
Covariates, State \& Year FE & $(0.0004)$ & $(0.0000)$ & $(0.0002)$ & $(0.0002)$ & $(0.0002)$ & $(0.0003)$ \\
\# of Observations & YES & YES & YES & YES & YES & YES \\
Adjusted R-squared & $9,558,621$ & $9,558,621$ & $9,558,621$ & $9,558,621$ & $9,558,621$ & $9,558,621$ \\
\hline
\end{tabular}

Note: Table D3 reports the results from DID estimations of 511 Systems adoption on a discrete choice of transportation modes to work. All covariates in Table D1 are included here but are omitted for brevity. Heteroscedasticity-adjusted standard errors, clustered at the state level, are included in parentheses. $* * * \mathrm{p}<0.01,{ }^{* *} \mathrm{p}<0.05, * \mathrm{p}<0.1$ 
Table D4. Effects of 511 Systems Adoption on Frequency and Distance of Daily Trips

\begin{tabular}{lcccc}
\hline \hline & $\begin{array}{c}\ln \text { (\# of } \\
\text { Person Trips) }\end{array}$ & $\begin{array}{c}\ln \text { (Mile of } \\
\text { Person Travel) }\end{array}$ & $\begin{array}{c}\ln \text { (\# of } \\
\text { Vehicle Trips) }\end{array}$ & $\begin{array}{c}\ln \text { (Miles of } \\
\text { Vehicle Travel) }\end{array}$ \\
\cline { 2 - 5 } & $(1)$ & $(2)$ & $(3)$ & $(4)$ \\
\hline & $-0.007^{* * *}$ & $-0.035^{* * *}$ & $-0.016^{* * *}$ & $-0.049^{* * *}$ \\
ITS & $(0.002)$ & $(0.006)$ & $(0.005)$ & $(0.007)$ \\
Covariates, Census Tract \& Year FE & YES & YES & YES & YES \\
\# of Observations & 43,323 & 43,322 & 43,323 & 43,309 \\
\# of Census Tracts & 28,834 & 28,834 & 28,833 & 28,821 \\
Adjusted R-squared & 0.969 & 0.956 & 0.943 & 0.950 \\
\hline
\end{tabular}

Note: Table D4 reports the effect of 511 Systems adoption on frequency and distance of personal and vehicle trips. The data is retrieved from the National Household Travel Survey (NHTS) in 2001 and 2010. These statistics are aggregated to the census tract level. Per NHTS documentation, Person Trips means a trip by one person in any mode of transportation, Person Miles of Travel means the number of miles traveled by each person on a trip, Vehicle trips means a trip by a single privately-operated vehicle, regardless of the number of persons in the vehicle, and Vehicle Miles of Travel means one vehicle mile of travel is the movement of one privately operated vehicle for one mile, regardless of the number of persons in the vehicle. Heteroscedasticityadjusted standard errors, clustered at the census tract level, are included in parentheses. $* * * \mathrm{p}<0.01, * * \mathrm{p}<0.05,{ }^{*} \mathrm{p}<0.1$

Table D5. Effects of 511 Systems Adoption on Travel Time Uncertainty

\begin{tabular}{lcc}
\hline \hline & Travel Time Uncertainty & Travel Time Uncertainty \\
& Based on TTI & Based on TTI \\
\cline { 2 - 3 } & $(1)$ & $(2)$ \\
\hline ITS & $-1.244^{* * *}$ & $-1.219^{* * *}$ \\
& $(0.052)$ & $(0.053)$ \\
Covariates, MSA \& Year FE & YES & YES \\
\# of Observations & 2,055 & 2,046 \\
Adj. R-squared & 0.659 & 0.660 \\
\hline
\end{tabular}

Note: Table D5 reports the results from the DID regressions on travel time uncertainty. Heteroscedasticity-adjusted standard errors, clustered at the MSA level, are included in parentheses. ${ }^{* * *} \mathrm{p}<0.01,{ }^{* *} \mathrm{p}<0.05,{ }^{*} \mathrm{p}<0.1$

Table D6. Effects of 511 Systems Adoption on Route Choice

\begin{tabular}{|c|c|c|c|}
\hline & $\begin{array}{c}\% \text { of Traffic in } \\
\text { Highway } \\
(\% \text { VMT) }\end{array}$ & $\begin{array}{c}\text { of Traffic in } \\
\text { Major Road } \\
(\% \mathrm{VMT})\end{array}$ & $\begin{array}{c}\% \text { of Traffic in } \\
\text { Local Road } \\
(\% \mathrm{VMT})\end{array}$ \\
\hline & $(1)$ & $(2)$ & (3) \\
\hline ITS & $\begin{array}{c}-0.002 \\
(0.009)\end{array}$ & $\begin{array}{c}-0.035 * * * \\
(0.013)\end{array}$ & $\begin{array}{l}-0.010 \\
(0.007)\end{array}$ \\
\hline Covariates, MSA \& Year FE & YES & YES & YES \\
\hline \# of Observations & 2,079 & 2,079 & 2,079 \\
\hline \# of MSAs & 99 & 99 & 99 \\
\hline Adj. R-squared & 0.496 & 0.324 & 0.438 \\
\hline
\end{tabular}

Note: Table D6 reports the results from the DID estimation of 511 Systems adoption on traffic allocated to different classes of roads. We control for miles shares of each road types. Heteroscedasticity-adjusted standard errors, clustered at the MSA level, are included in parentheses. ${ }^{* * *} \mathrm{p}<0.01, * * \mathrm{p}<0.05, * \mathrm{p}<0.1$ 
Table D7. Effects of 511 Systems and Road Supply on Traffic Congestion

\begin{tabular}{lcccc}
\hline \hline & \multicolumn{3}{c}{ COST } & \multicolumn{2}{c}{ TIME } \\
\cline { 2 - 5 } & $(1)$ & $(2)$ & $(3)$ & $(4)$ \\
\hline ITS & $-0.028^{* * *}$ & -0.019 & $-0.025^{* * *}$ & -0.021 \\
Road & $(0.007)$ & $(0.021)$ & $(0.007)$ & $(0.019)$ \\
& $1.024 * * *$ & $1.033 * * *$ & 0.026 & 0.034 \\
Road $\times$ ITS & $(0.036)$ & $(0.037)$ & $(0.034)$ & $(0.035)$ \\
& & $-0.004 * * *$ & & $-0.003 * * *$ \\
Covariates, MSA \& Year FE & & $(0.001)$ & & $(0.001)$ \\
\# of Observations & YES & YES & YES & YES \\
Adj. R-squared & 2,079 & 2,079 & 2,079 & 2,079 \\
\hline
\end{tabular}

Note: Table D7 reports the results on the interaction effect of road supply and ITS. Heteroscedasticity-adjusted standard errors, clustered at the MSA level, are included in parentheses. ${ }^{* *} \mathrm{p}<0.01, * * \mathrm{p}<0.05,{ }^{*} \mathrm{p}<0.1$

Table D8. Effects of 511 Systems and Public Transit Services on Traffic Congestion

\begin{tabular}{|c|c|c|c|c|c|c|c|c|}
\hline & \multicolumn{2}{|c|}{ COST } & \multicolumn{2}{|c|}{ TIME } & \multicolumn{2}{|c|}{ COST } & \multicolumn{2}{|c|}{ TIME } \\
\hline & $(1)$ & $(2)$ & (3) & (4) & $(5)$ & $(6)$ & $(7)$ & $(8)$ \\
\hline ITS & $\begin{array}{c}-0.027 * * * \\
(0.007)\end{array}$ & $\begin{array}{l}-0.019 \\
(0.022)\end{array}$ & $\begin{array}{c}-0.025 * * * \\
(0.007)\end{array}$ & $\begin{array}{l}-0.006 \\
(0.021)\end{array}$ & $\begin{array}{c}-0.029 * * * \\
(0.007)\end{array}$ & $\begin{array}{c}0.003 \\
(0.016)\end{array}$ & $\begin{array}{c}-0.026^{* * *} \\
(0.007)\end{array}$ & $\begin{array}{c}0.018 \\
(0.015)\end{array}$ \\
\hline Bus & $\begin{array}{c}0.016 * * * \\
(0.006)\end{array}$ & $\begin{array}{c}0.016 * * * \\
(0.006)\end{array}$ & $\begin{array}{c}0.014 * * \\
(0.006)\end{array}$ & $\begin{array}{c}0.014 * * * \\
(0.005)\end{array}$ & & & & \\
\hline Bus $\times$ ITS & & $\begin{array}{c}0.000 \\
(0.004)\end{array}$ & & $\begin{array}{l}-0.004 \\
(0.003)\end{array}$ & & & & \\
\hline Rail & & & & & $\begin{array}{l}-0.004 \\
(0.006)\end{array}$ & $\begin{array}{l}-0.003 \\
(0.006)\end{array}$ & $\begin{array}{l}-0.003 \\
(0.005)\end{array}$ & $\begin{array}{l}-0.002 \\
(0.005)\end{array}$ \\
\hline Rail $\times$ ITS & & & & & & $\begin{array}{c}-0.007 * * \\
(0.003)\end{array}$ & & $\begin{array}{c}-0.009 * * * \\
(0.003)\end{array}$ \\
\hline All Covariates & YES & YES & YES & YES & YES & YES & YES & YES \\
\hline MSA \& Year FE & YES & YES & YES & YES & YES & YES & YES & YES \\
\hline \# of Observations & 2,079 & 2,079 & 2,079 & 2,079 & 1,813 & 1,813 & 1,813 & 1,813 \\
\hline Adjusted R-squared & 0.955 & 0.955 & 0.954 & 0.954 & 0.959 & 0.959 & 0.959 & 0.960 \\
\hline
\end{tabular}




\section{Online Supplementary Appendix E. The Use of ITS}

Table E1. Effects of 511 Use on Traffic Congestion (Data: 2010-2014)

\begin{tabular}{|c|c|c|}
\hline & $\begin{array}{c}(1) \\
\text { COST }\end{array}$ & $\begin{array}{c}(2) \\
\text { TIME }\end{array}$ \\
\hline $\ln (1+$ number of 511 calls $)$ & $\begin{array}{c}0.002 \\
(0.013)\end{array}$ & $\begin{array}{c}0.009 \\
(0.013)\end{array}$ \\
\hline $\ln (1+$ number of 511 website visits $)$ & $\begin{array}{c}-0.019 * * \\
(0.008)\end{array}$ & $\begin{array}{c}-0.016 * \\
(0.009)\end{array}$ \\
\hline All Covariates & YES & YES \\
\hline MSA FE & YES & YES \\
\hline Year FE & YES & YES \\
\hline Number of MSAs & 42 & 42 \\
\hline Observations & 210 & 210 \\
\hline Adj. R-squared & 0.356 & 0.560 \\
\hline
\end{tabular}

Table E2. Effects of Different 511 Functionality on Traffic Congestion (Data: 1994-2005)

\begin{tabular}{|c|c|c|c|c|}
\hline & COST & TIME & COST & TIME \\
\hline ITS & $-0.017^{*}$ & $-0.014 *$ & -0.025 & -0.020 \\
\hline & $(0.009)$ & $(0.008)$ & $(0.022)$ & $(0.023)$ \\
\hline ITS $\times$ Weather Info & & & $\begin{array}{l}-0.002 \\
(0.051)\end{array}$ & $\begin{array}{l}-0.006 \\
(0.051)\end{array}$ \\
\hline ITS $\times$ Road Condition Info. & & & $\begin{array}{c}-0.159 * \\
(0.095)\end{array}$ & $\begin{array}{c}-0.177 * * \\
(0.089)\end{array}$ \\
\hline ITS $\times$ Incidents Info. & & & $\begin{array}{c}0.089 \\
(0.093)\end{array}$ & $\begin{array}{c}0.098 \\
(0.091)\end{array}$ \\
\hline ITS $\times$ Congestion Info. & & & $\begin{array}{c}-0.153 * * \\
(0.069)\end{array}$ & $\begin{array}{c}-0.161 * * \\
(0.067)\end{array}$ \\
\hline ITS $\times$ Travel Time Info. & & & $\begin{array}{l}-0.103 \\
(0.105)\end{array}$ & $\begin{array}{l}-0.168^{*} \\
(0.100)\end{array}$ \\
\hline ITS $\times$ Variable Message Signs & & & $\begin{array}{c}0.122 \\
(0.112)\end{array}$ & $\begin{array}{c}0.132 \\
(0.106)\end{array}$ \\
\hline ITS $\times 511$ Website & & & $\begin{array}{c}-0.093 * * * \\
(0.026)\end{array}$ & $\begin{array}{c}-0.093 * * * \\
(0.024)\end{array}$ \\
\hline All Covariates & YES & YES & YES & YES \\
\hline MSA FE & YES & YES & YES & YES \\
\hline Year FE & YES & YES & YES & YES \\
\hline \# of Observations & 912 & 912 & 912 & 912 \\
\hline \# of MSAs & 76 & 76 & 76 & 76 \\
\hline Adjusted R-squared & 0.973 & 0.969 & 0.974 & 0.970 \\
\hline
\end{tabular}

Note: The data about functionalities of 511 Systems is from a report, entitled "Implementation and Operational Guidelines for 511 Services" (September 2005), published by 511 Deployment Coalition. The data for years after 2005 is not available so that we only use the main dataset until 2005 for this analysis. The functionalities include which information each state 511 Systems made available to the public and through which channels. Note that all states that adopted 511 systems automatically opened up the 511 call services. Therefore, the estimates on the ITS can capture the effect of 511 call services. All other functionality variables are cross-sectional and thus we interact them with ITS variable to avoid being absorbed by the MSA fixed effects. Heteroscedasticity-adjusted standard errors, clustered at the MSA level, are included in parentheses. ${ }^{* * *} \mathrm{p}<0.01,{ }^{* *} \mathrm{p}<0.05,{ }^{*} \mathrm{p}<0.1$ 
Table E3: Effects of 511 Systems Adoption and Its Funding on Traffic Congestion (Data: 1994-2011)

\begin{tabular}{lcccc}
\hline \hline & $(1)$ & $(2)$ & $(3)$ & $(4)$ \\
VARIABLES & COST & COST & TIME & TIME \\
\hline ITS & $-0.023 * * *$ & -0.021 & $-0.022 * * *$ & -0.020 \\
& $(0.008)$ & $(0.017)$ & $(0.008)$ & $(0.017)$ \\
$\ln$ (Federal Funding) & 0.001 & 0.001 & 0.001 & 0.001 \\
& $(0.001)$ & $(0.001)$ & $(0.001)$ & $(0.001)$ \\
ITS $\times \ln$ (Federal Funding) & & $-0.002 * *$ & & $-0.002 * * *$ \\
& & $(0.001)$ & & $(0.001)$ \\
All Covariates & YES & YES & YES & YES \\
MSA FE & YES & YES & YES & YES \\
Year FE & YES & YES & YES & YES \\
\# of Observations & 1,782 & 1,782 & 1,782 & 1,782 \\
\# of MSAs & 99 & 99 & 99 & 99 \\
Adjusted R-squared & 0.960 & 0.960 & 0.957 & 0.957 \\
\hline
\end{tabular}

Note: The data of federal funding for 511 Systems design, deployment, and modification is retrieved from the Federal Aid archive. The federal funding data is not available after 2011, and thus, we use the time frame of 1994-2011 for this analysis. The Federal Aid dataset records most of the funding (except for a few California counties) allocation for 511 Systems at the state level. For MSAs within the same state, since they access to homogeneous 511 Systems, we constructed a funding measure for these MSAs as the same as their state-level measure. For MSAs spanning across multiple states (e.g., Philadelphia-Camden-Wilmington, PA-NJ-DE-MD, MSA), we constructed a weighted-average measure for 511 Systems funding using a weight measured by road miles-percentages of MSA in each state in the same way we constructed the primary measure for 511 System adoption in the preceding analysis. We matched the funding data to our main dataset of traffic congestion and time-varying covariates, and we used the amount of federal funding for 511 Systems as the independent variable. Heteroscedasticity-adjusted standard errors, clustered at the MSA level, are included in parentheses. ${ }^{* * *} \mathrm{p}<0.01, * * \mathrm{p}<0.05,{ }^{*} \mathrm{p}<0.1$

Table E4: Heterogeneous Effects of 511 Systems Adoption across Population Size

\begin{tabular}{|c|c|c|c|c|}
\hline & \multicolumn{2}{|c|}{ COST } & \multicolumn{2}{|c|}{ TIME } \\
\hline & (1) & (2) & (3) & (4) \\
\hline ITS & $\begin{array}{c}-0.029 * * * \\
(0.006)\end{array}$ & $\begin{array}{c}0.002 \\
(0.010)\end{array}$ & $\begin{array}{c}-0.026 * * * \\
(0.006)\end{array}$ & $\begin{array}{c}0.006 \\
(0.010)\end{array}$ \\
\hline ITS $\times$ SMALL MSA & \multicolumn{2}{|c|}{ Omitted Baseline } & \multicolumn{2}{|c|}{ Omitted Baseline } \\
\hline ITS $\times$ MEDIUM MSA & & $\begin{array}{l}-0.009 \\
(0.011)\end{array}$ & & $\begin{array}{c}-0.012 \\
(0.011)\end{array}$ \\
\hline ITS $\times$ LARGE MSA & & $\begin{array}{c}-0.027 * * \\
(0.011)\end{array}$ & & $\begin{array}{c}-0.031 * * * \\
(0.011)\end{array}$ \\
\hline ITS $\times$ VERY MSA & & $\begin{array}{c}-0.045^{* * * *} \\
(0.011)\end{array}$ & & $\begin{array}{c}-0.050^{* * *} \\
(0.011)\end{array}$ \\
\hline All Covariates & YES & YES & YES & YES \\
\hline MSA FE & YES & YES & YES & YES \\
\hline YEAR FE & YES & YES & YES & YES \\
\hline \# of Observations & 2,079 & 2,079 & 2,079 & 2,079 \\
\hline \# of MSAs & 99 & 99 & 99 & 99 \\
\hline Adj. R-squared & 0.956 & 0.974 & 0.954 & 0.974 \\
\hline
\end{tabular}

Note: Table E4 compares the effects of 511 Systems across different MSA sizes. Following the classification by the AUMS dataset, we use dummy variables to indicate MSA sizes - very large MSAs (more than 3 million population), large MSAs ( 1 million to 3 million population), medium MSAs (500,000 to 1 million population), and small MSAs (less than 500,000 population). We then interacted these variables with the 511 Systems adoption and replicated the estimation. Heteroscedasticity-adjusted standard errors, clustered at the MSA level, are included in parentheses. ${ }^{* * *} \mathrm{p}<0.01,{ }^{* *} \mathrm{p}<0.05,{ }^{*} \mathrm{p}<0.1$ 


\section{Table E5: Heterogeneous Effects of 511 Systems Adoption}

across Distinct Levels of Traffic Congestion

\begin{tabular}{|c|c|c|c|c|c|c|c|c|c|}
\hline \multirow[b]{2}{*}{ Decile } & \multicolumn{9}{|c|}{ Congestion Measure at Different Deciles } \\
\hline & 0.10 & 0.20 & 0.30 & 0.40 & 0.50 & 0.60 & 0.70 & 0.80 & 0.90 \\
\hline \multicolumn{10}{|c|}{ Panel A: Congestion is measured by COST } \\
\hline ITS & $\begin{array}{c}0.001 \\
(0.007)\end{array}$ & $\begin{array}{c}-0.003 \\
(0.003)\end{array}$ & $\begin{array}{c}-0.016^{* * *} \\
(0.005)\end{array}$ & $\begin{array}{l}-0.017^{*} \\
(0.010)\end{array}$ & $\begin{array}{c}-0.031 * * * \\
(0.003)\end{array}$ & $\begin{array}{c}-0.031 * * * \\
(0.001)\end{array}$ & $\begin{array}{c}-0.045^{* * *} \\
(0.001)\end{array}$ & $\begin{array}{c}-0.050 * * * \\
(0.000)\end{array}$ & $\begin{array}{c}-0.051 * * * \\
(0.001)\end{array}$ \\
\hline \multicolumn{10}{|c|}{ Panel B: Congestion is measured by TIME } \\
\hline ITS & $\begin{array}{c}-0.004 \\
(0.005)\end{array}$ & $\begin{array}{c}-0.007 \\
(0.004)\end{array}$ & $\begin{array}{c}-0.014 * * \\
(0.006)\end{array}$ & $\begin{array}{c}-0.023 * * * \\
(0.000)\end{array}$ & $\begin{array}{c}-0.022 * * * \\
(0.001)\end{array}$ & $\begin{array}{c}-0.027 * * * \\
(0.000)\end{array}$ & $\begin{array}{c}-0.022 * * * \\
(0.001)\end{array}$ & $\begin{array}{c}-0.025 * * * \\
(0.001)\end{array}$ & $\begin{array}{c}-0.025 * * * \\
(0.000)\end{array}$ \\
\hline Covariates & YES & YES & YES & YES & YES & YES & YES & YES & YES \\
\hline MSA FE & YES & YES & YES & YES & YES & YES & YES & YES & YES \\
\hline Year FE & YES & YES & YES & YES & YES & YES & YES & YES & YES \\
\hline
\end{tabular}

\section{References}

Burchfield M, Overman HG, Puga D, Turner MA (2006) Causes of sprawl: A portrait from space. The Quarterly Journal of Economics 121(2):587-633.

Cutler DM, Glaeser EL (1997) Are ghettos good or bad? The Quarterly Journal of Economics 112(3):827-872.

Duranton G, Turner MA (2011) The fundamental law of road congestion: Evidence from US cities. The American Economic Review 101(6):2616-2652.

Duranton G, Turner MA (2012) Urban growth and transportation. Review of Economic Studies 79(4):1407-1440.

Gong J, Greenwood BN, Song Y (2018) Uber Might Buy Me a Mercedes Benz: An Empirical Investigation of the Sharing Economy and Durable Goods Purchase (Social Science Research Network, Rochester, NY).

Gopal A, Greenwood BN (2017) Traders, guns, and money: The effects of mass shootings on stock prices of firearm manufacturers in the U.S. PLoS ONE 12(5): $\mathrm{e} 0177720$.

Stock JH, Yogo M (2002) Testing for weak instruments in linear IV regression (National Bureau of Economic Research Cambridge, Mass., USA).

US Department of Transportation, Federal Highway Administration (2005) Implementation and Operational Guidelines for 511 Services, Version 3.0. 511 Deployment Coalition. Retrieved (January 5, 2019), https://ops.fhwa.dot.gov/511/resources/publications/511guide ver3/511guide3.htm. 